\title{
Rhizobium leguminosarum bv. trifolii ros $R$ is required for interaction with clover, biofilm formation and adaptation to the environment
}

\author{
Monika Janczarek ${ }^{1 *}$, Jolanta Kutkowska ${ }^{1}$, Tomasz Piersiak², Anna Skorupska
}

\begin{abstract}
Background: Rhizobium leguminosarum bv. trifolii is a symbiotic nitrogen-fixing bacterium that elicits nodules on roots of host plants Trifolium spp. Bacterial surface polysaccharides are crucial for establishment of a successful symbiosis with legumes that form indeterminate-type nodules, such as Trifolium, Pisum, Vicia, and Medicago spp. and aid the bacterium in withstanding osmotic and other environmental stresses. Recently, the R. leguminosarum bv. trifolii RosR regulatory protein which controls exopolysaccharide production has been identified and characterized.
\end{abstract}

Results: In this work, we extend our earlier studies to the characterization of rosR mutants which exhibit pleiotropic phenotypes. The mutants produce three times less exopolysaccharide than the wild type, and the lowmolecular-weight fraction in that polymer is greatly reduced. Mutation in ros $R$ also results in quantitative alterations in the polysaccharide constituent of lipopolysaccharide. The ros $R$ mutants are more sensitive to surface-active detergents, antibiotics of the beta-lactam group and some osmolytes, indicating changes in the bacterial membranes. In addition, the rosR mutants exhibit significant decrease in motility and form a biofilm on plastic surfaces, which differs significantly in depth, architecture, and bacterial viability from that of the wild type. The most striking effect of rosR mutation is the considerably decreased attachment and colonization of root hairs, indicating that the mutation affects the first stage of the invasion process. Infection threads initiate at a drastically reduced rate and frequently abort before they reach the base of root hairs. Although these mutants form nodules on clover, they are unable to fix nitrogen and are outcompeted by the wild type in mixed inoculations, demonstrating that functional ros $R$ is important for competitive nodulation.

Conclusions: This report demonstrates the significant role RosR regulatory protein plays in bacterial stress adaptation and in the symbiotic relationship between clover and R. leguminosarum bv. trifolii 24.2.

\section{Background}

Nitrogen-fixing symbiotic bacteria, commonly known as rhizobia, employ a variety of strategies which allow them to exist in the soil and adapt to various environmental conditions prior to infecting leguminous plant hosts. Rhizobial cell surface components, exopolysaccharide (EPS) and lipopolysaccharide (LPS), play an important role in determining the symbiotic competence of rhizobia, root tissue invasion and induction of nitrogen-fixing nodules on host plants forming indeterminate-type nodules, such

\footnotetext{
* Correspondence: mon.jan@poczta.umcs.lublin.pl

'Department of Genetics and Microbiology, University of M. Curie-

Skłodowska, Akademicka 19, 20-033 Lublin, Poland Full list of author information is available at the end of the article
}

as Pisum, Trifolium, Vicia, and Medicago spp. [1-4]. Acidic EPSs secreted in large amounts by rhizobia are speciesspecific compounds consisting of common sugars substituted with non-carbohydrate residues [1,4-6]. EPS of Rhizobium leguminosarum is a heteropolymer consisting of octasaccharide subunits composed of five glucose residues, one galactose, and two glucuronic acid residues, additionally decorated with acetyl, pyruvyl, and 3-hydroxybutyryl groups $[7,8]$. EPS-deficient mutants or those with an altered LPS structure are impaired in nodule cell invasion and nitrogen fixation [1,6,9-11]. Biosynthesis of EPS in $R$. leguminosarum is a multi-step process requiring the expression of several pss genes, located in the major EPS cluster on the chromosome $[12,13]$. This region includes
C Biomed Central 
pss genes encoding specific glycosyl transferases, epimerases and deacetylases involved in the biosynthesis of EPS repeating units, genes encoding proteins engaged in the polymerization and transport of EPS, and other genes that code for EPS modifying enzymes [12,13]. As has been established for $R$. leguminosarum and Sinorhizobium (Ensifer) meliloti, EPS plays an important role in biofilm development, being the major matrix component [14-17]. A mutation in $R$. leguminosarum pssA encoding the first IP-glucosyl transferase essential for EPS synthesis completely abolishes biofilm development [14,18]. Glycanases PlyA and PlyB secreted via the PrsD-PrsE type I secretion system are responsible for EPS modification and biofilm formation. PlyA and PlyB cleave mature EPS. Exopolysaccharides produced by prs $D, p l y B$, and plyBplyA mutants form significantly longer polymers than the wild type $[19,20]$. Besides glycanases, RapC, RapA1, and RapA2 agglutinins engaged in the adhesion and aggregation of rhizobia are secreted via the PrsD-PrsE type I secretion system $[14,21,22]$.

In a previous study, a ros $R$ gene encoding a positive transcriptional regulator of EPS synthesis was identified in $R$. leguminosarum bv. trifolii [23]. The chromosomally located rosR shares significant identity with rosR of $R h i$ zobium etli [24], mucR of Sinorhizobium meliloti [25], ros of Agrobacterium tumefaciens [26], and rosAR of Agrobacterium radiobacter [27]. Transcriptional regulators encoded by these genes belong to the family of Ros/MucR proteins which possess a $\mathrm{Cys}_{2} \mathrm{His}_{2}$ type zincfinger motif and are involved in positive or negative regulation of EPS synthesis. A genome-wide genetic screening has revealed that $R$. etli ros $R$ affects the expression of about fifty genes, among them those responsible for the synthesis, polymerization, and transport of surface polysaccharides [28]. rosR of $R$. leguminosarum bv. trifolii encodes a protein of 143 aa (15.7 $\mathrm{kDa}$ ) containing a zinc-finger motif in its C-terminal domain that binds a 22-bp-long consensus sequence called the RosR-box, which is located in the rosR upstream region. Besides the RosR-box, several regulatory sites have been identified in the ros $R$ upstream region, including two $\mathrm{P} 1$ and $\mathrm{P} 2$ promoters and three motifs resembling the $E$. coli cAMP-CRP binding site, indicating a complex regulation of $\operatorname{ros} R$ expression $[23,29]$. RosR binding to the RosR-box negatively regulates transcription of its own gene [23]. In the presence of glucose, the transcriptional activity of the ros $R$ is significantly reduced, showing that the expression of this gene is regulated by catabolic repression.

ros $R$ mutation in $R$. leguminosarum bv. trifolii causes a substantially diminished EPS production and ineffective symbiosis with clover [30]. In contrast, although an $R$. etli ros $R$ mutant also formed colonies with altered morphology, it retained the ability to elicit nitrogen- fixing nodules on Phaseolus vulgaris, which forms determinate-type nodules [24]. The nodulation competitiveness of this mutant, however, was greatly reduced and, for this reason, rosR was assumed to be a determinant of $R$. etli competitiveness.

In this study, we describe pleiotropic phenotypes of ros $R$ mutants, which are characterized by an increased sensitivity to osmotic stresses, detergents, and antibiotics that affect peptidoglycan synthesis. These mutants produce significantly less EPS than the wild type and form an altered biofilm on polystyrene surfaces. Moreover, the mutation in $\operatorname{ros} R$ affects symbiotic performance, strikingly decreasing bacterial attachment to clover root hairs and formation of infection threads.

\section{Results}

\section{$R$. leguminosarum bv. trifolii ros $R$ mutants}

Recently, we described $R$. leguminosarum bv. trifolii 24.2 derivatives mutated in the ros $R$ open reading frame (Rt2440 and Rt2472) [23,29]. In this study, using integrative mutagenesis, the Rt2441 mutant was constructed in which a fragment containing the 5 '-end regulatory region and the first 60 nucleotide triplets for RosR was integrated 360 bp upstream of genomic rosR ORF, just before the P1 promoter (Figure $1 \mathrm{~B}$ ). We wanted to examine the effect of duplication of regulatory sequences consisting of two RosR-boxes, which constitute the sites of interaction with the zinc finger motif of the RosR transcription factor, on several phenotypic and symbiotic properties of the mutant.

The two previously described rosR mutants (Rt2440 and Rt2472) were also evaluated in some assays (Figure 1). The Rt2440 mutant has 1 bp deletion $(\triangle \mathrm{C} 177)$ in rosR ORF, resulting in a frameshift mutation and a subsequent synthesis of RosR with a non-native amino acid sequence downstream of the mutation [23]. The Rt2472 mutant was obtained by gene replacement mutagenesis using the mini-Tn5 transposon inserted between 151-152 nt of rosR ORF [30].

\section{$R$. leguminosarum ros $R$ mutants are defective in symbiotic efficiency and competitiveness}

All rosR mutants demonstrated similar colony phenotypes; they formed characteristic dry, wrinkled colonies with many clumps on 79CA agar medium (data not shown). Clover inoculated with the ros $R$ mutants formed nodules with a 7-day delay, and their number was about two-fold lower in comparison to the wild type (Table 1). Inoculated plants turned yellowish, which indicated inefficient symbiosis, and the fresh mass of shoots was, on average, $69.2 \%$ of the aerial parts of plants inoculated with Rt24.2. Irrespective of the type of rosR mutation, wild type copies of ros $R$ carried on the low-copy plasmid pRC24 fully complemented the mutation. Transconjugants were mucoid 


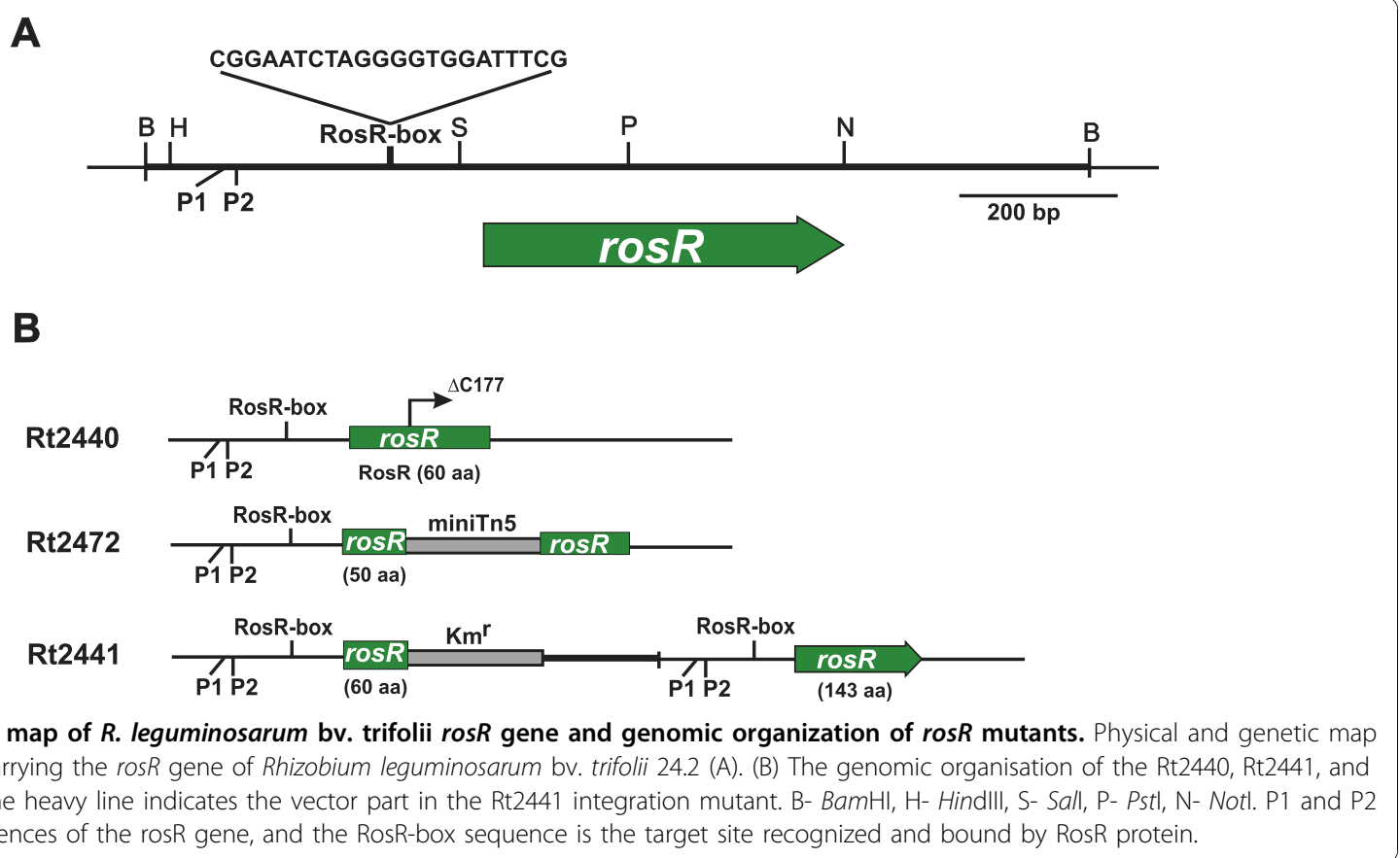

$\left(\mathrm{EPS}^{+}\right)$, and clover inoculated with the clones demonstrated symbiotic phenotypes similar to the wild type (Table 1).

To study the competitive ability of the Rt2472 and the Rt2441 mutants, clover seedlings were inoculated with mixtures of each rosR mutant with Rt24.2 wild type in various proportions. For both mutants, in the case of a 1:1 strain ratio, the nodules were colonized exclusively by the Rt24.2 wild type. In 10:1, 100:1, and 1000:1 strain mixtures, the percentage of nodules occupied by the Rt 2472 mutant was $1 \%, 2.5 \%$ and $9 \%$ of the sampled nodules, respectively (details not shown). The Rt2441 mutant demonstrated a similar decrease in competitiveness: the percentages of occupied nodules were $1 \%$,
$4.4 \%$, and $11.1 \%$ in the $10: 1,100: 1$, and $1000: 1$ mixtures, respectively. The results indicated that rosR mutation substantially reduced the nodulation competitiveness of R. leguminosarum bv. trifolii 24.2 .

rosR mutants are altered in surface polysaccharides Non-mucoid colonies formed by the rosR mutants indicated that the strains produced reduced amounts of surface polysaccharides. The amounts of EPS secreted by Rt2440, Rt2441 and Rt2472 were estimated to be about $30 \%$ of the amount formed by the wild type (Table 1 ). Rt2441, bearing a truncated $\operatorname{ros} R$ and an additional wild type copy of the gene, demonstrated the negative dominant nature of rosR mutation.

Table 1 ros $R$ mutation affects symbiotic properties and EPS production of $R$. leguminosarum bv. trifolii 24.2. Defects are fully complemented by the wild-type ros $R$ copy.

\begin{tabular}{|c|c|c|c|c|}
\hline \multirow[t]{2}{*}{ Strain/plasmid } & \multirow[t]{2}{*}{ Nodule no. per plant ${ }^{a}$} & \multicolumn{2}{|c|}{ Shoot weight (mg/plant) ${ }^{a}$} & \multirow[t]{2}{*}{ EPS $(\mathrm{mg} / \mathrm{mg})^{\mathrm{b}}$} \\
\hline & & (fresh wt) & (dry wt) & \\
\hline Rt2440 & $5.1 \pm 1.9$ & $42.4 \pm 11.4$ & $4.3 \pm 0.15$ & $0.31 \pm 0.03$ \\
\hline Rt2441 & $6.2 \pm 2.1$ & $44.8 \pm 10.2$ & $4.9 \pm 0.20$ & $0.36 \pm 0.04$ \\
\hline Rt2472 & $4.9 \pm 1.7$ & $43.2 \pm 7.7$ & $4.2 \pm 0.10$ & $0.30 \pm 0.03$ \\
\hline Rt2440(pRC24) & $12.3 \pm 3.1$ & $59.3 \pm 12.5$ & $6.1 \pm 0.25$ & $1.19 \pm 0.07$ \\
\hline Rt2441(pRC24) & $12.5 \pm 3.6$ & $58.8 \pm 10.2$ & $6.0 \pm 0.2$ & $1.15 \pm 0.05$ \\
\hline Rt2472(pRC24) & $12.7 \pm 5.4$ & $61.2 \pm 14.2$ & $6.2 \pm 0.3$ & $1.21 \pm 0.06$ \\
\hline Rt24.2 (wild type) & $12.8 \pm 2.9$ & $62.8 \pm 12.1$ & $6.2 \pm 0.25$ & $0.97 \pm 0.05$ \\
\hline Uninoculated clover & - & $34.7 \pm 6.4$ & $3.8 \pm 0.10$ & - \\
\hline
\end{tabular}

${ }^{a}$ Plants were harvested 28 days after inoculation. Given values ( \pm standard deviation) are averages of three independent experiments with 20 plants for each treatment.

b - Exopolysaccharide (EPS) production (Glc equivalents in $\mathrm{mg} / \mathrm{mg}$ of protein). 


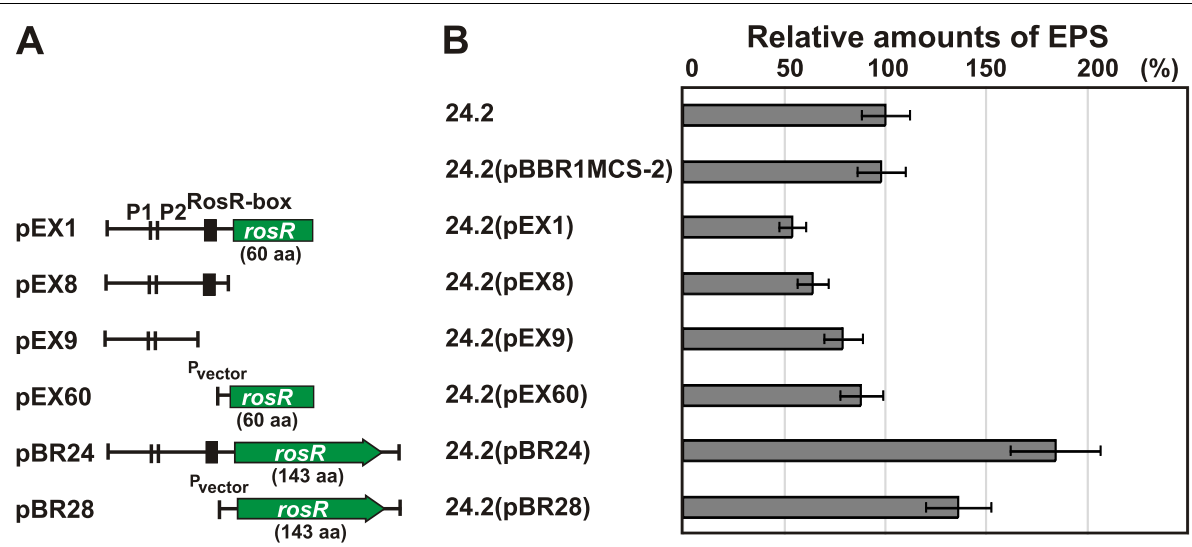

Figure 2 The effect of additional copies of different regulatory rosR sequences on the EPS production by $R$. leguminosarum. Data shown are the means of three replicates \pm SD.

To test the negative dominant effect on EPS production observed in Rt2441, plasmids containing different fragments of the regulatory region and $\operatorname{ros} R$ were constructed on pBBR1MCS backbone and introduced into Rt 24.2 (Figure 2). The pEX1 plasmid containing the same fragment as in the Rt2441 mutant genome exerted a strong negative effect on EPS production, decreasing EPS synthesis to $54 \%$ of the control (Figure 2). Rt24.2(pEX8), containing exclusively the rosR upstream region with the RosR-box, produced 64\% EPS of the wild type strain, but Rt24.2(pEX60), which contained only the shortened rosR ORF, produced $88 \%$ of Rt 24.2 EPS. Only after introducing full-length copies of rosR into Rt24.2 (especially under its own promoter, on plasmid pBR24), the negative dominant effect had been overcome, with the increase of EPS synthesis up to $183 \%$ of the control. These results suggested that additional copies of the ros $R$ upstream region with the RosR-box sequence, rather than RosR protein deprived of the C-terminal DNA binding domain, affected the level of EPS production. Most likely, the positive regulation of EPS synthesis by RosR depends on an equilibrium between $\operatorname{ros} R$ regulatory sequences and the amount of RosR. These results explain, to some extent, the phenotype of the Rt2441 mutant.

EPSs isolated from the Rt24.2 wild type and Rt 2440 and Rt2441 ros $R$ mutants were fractionated by gel permeation chromatography on a Bio-Gel A-5m column, and two fractions of EPS with significantly different molecular weights were obtained (Figure 3A). The ratio of highmolecular-weight (HMW) to low-molecular-weight (LMW) fractions was 68\%:32\% in the EPS of Rt24.2 wild type. In the Rt2440 and Rt2441 rosR mutants, a considerable change was observed in the HMW to LMW EPS ratio in favor of $\mathrm{HMW}$, i.e., $79 \%: 21 \%$ and $76 \%: 24 \%$, respectively. To establish the sugar composition of EPS of the wild type and the rosR mutant, peak samples from Bio-Gel A-5m chromatography (Figure 3A) were evaluated for monosaccharide composition by GC-MS. The glucose/glucuronic acid/galactose ratio was found to be approximately $5: 2: 1$, which is characteristic of the acidic EPS of R. leguminosarum (Figure 3C). Additionally, non-carbohydrate substituents in the EPS of Rt2440 and Rt24.2 wild type were determined (Figure 3B-C). EPS secreted by the rosR mutant had a lower level of $\mathrm{O}$-acetyl and 3-hydroxybutyryl substitutions and slightly more pyruvyl substitutions in relation to the wild type EPS (Figure 3B).

To investigate whether the rosR mutation affected LPS synthesis, LPSs from Rt24.2, Rt2440, and Rt2441 were analyzed by SDS-PAGE (Figure 3D). The LPS of Rt 24.2 wild type separated into two intense bands: fast-migrating LPS II representing lipid A and the core oligosaccharide, and slow-migrating LPS I carrying the $\mathrm{O}$ antigen $[31,32]$. The appearance of faintly stained bands in the upper region of the gel indicated the presence of LPS forms with O-chains composed of more polymerized repeating units. LPS of Rt2440 had a similar profile; however, the intensity of the individual bands was much weaker than for Rt 24.2 (Figure 3D). High-molecular-weight LPS (LPS I) from the rosR mutant migrated slightly faster than LPS I of the wild type. In order to assign these changes, the glycosyl compositions of polysaccharides (PSs) obtained from the wild type and the Rt2440 mutant LPSs by mild acid hydrolysis were examined (Figure 3E). It was established that the sugar composition of both PSs was the same, although some differences in the amounts of individual components (especially 6-deoxyhexoses) were observed. The ratio of L-rhamnose to 6- L-deoxytalose was 1:1 in PS of the rosR mutant as compared to 2:1 in the wild type PS. Our preliminary results (R. Russa, personal communication) indicate that L-rhamnose and 6L-deoxytalose are compounds of both O-chain repeating units and a non-repeating glycosyl sequence of the outer core region. 
A

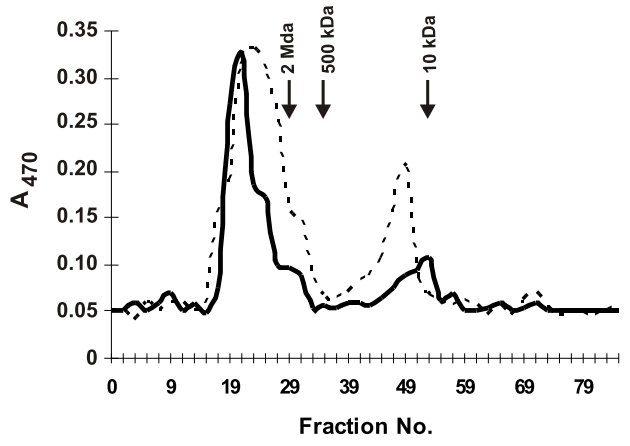

$\longrightarrow$ Rt $2440 \cdots \cdots \cdot$. Rt 24.2

B

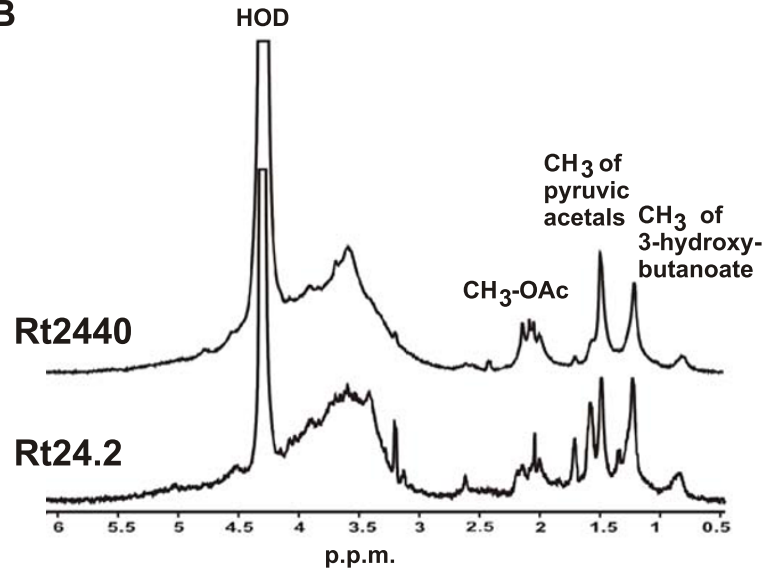

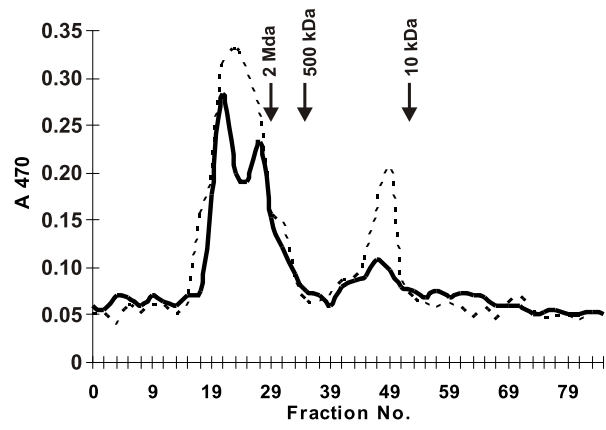

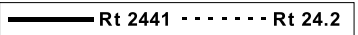

D
C

\begin{tabular}{lll}
\hline $\begin{array}{l}\text { EPS of } R \text {. leguminosarum } \\
\text { bv. trifolii }\end{array}$ & Rt24.2 & Rt2440 \\
\hline
\end{tabular}

Relative molar ratio of glycosyl components normalized to galactose

D-Glucose (D-GIc)

D-Galactose (D-Gal)

4.8

1.8

1.0

4.7

2.0

1.0

The ratio of non-carbohydrate substituents per repeating unit

O-Acetyl

Pyruvyl acetals

3-hydroxybutyryl

1.37

1.92

0.63
D-Glucuronic acid (D-GlcA)*

E

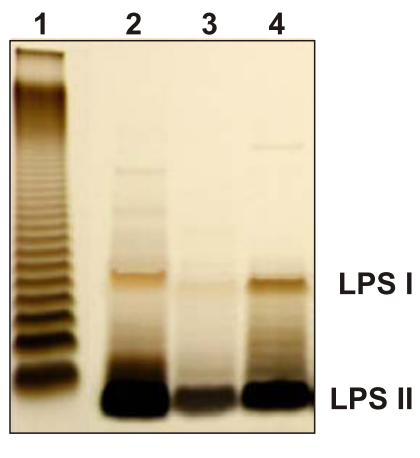

\begin{tabular}{|c|c|c|}
\hline \multirow[t]{2}{*}{ Sugar } & \multicolumn{2}{|c|}{$\begin{array}{l}\text { Relative mol\% of total } \\
\text { sugar composition }\end{array}$} \\
\hline & Rt24.2 & Rt2440 \\
\hline 6-deoxy-L-talose (L-dTal) & 13.8 & 17.8 \\
\hline L-Rhamnose (L-Rha) & 25.7 & 16.5 \\
\hline 2,3-di-O-methyl-D-galactose & & \\
\hline $\begin{array}{l}\left(2,3-\mathrm{Me}_{2}-\mathrm{Gal}\right) \\
2-\mathrm{N} \text {-acetamido-2 6- }\end{array}$ & 3.2 & 3.8 \\
\hline dideoxyglucose (QuiNAc) & 2.7 & 2.3 \\
\hline D-Mannose (D-Man) & 7.2 & 6.5 \\
\hline D-Glucose (D-Glc) & 2.5 & 4.0 \\
\hline D-Galactose (D-Gal) & 7.7 & 7.1 \\
\hline D-Galacturonic acid (D-GalA)* & 15.7 & 18.9 \\
\hline $\begin{array}{l}\text { 3-deoxy-lyxo-2-heptulosaric } \\
\text { acid (DHA) }\end{array}$ & 99 & 93 \\
\hline 3-deoxy-D-manno-2- & & \\
\hline octulosonic acid (KDO) & 11.6 & 13.8 \\
\hline
\end{tabular}

* Determined as the carboxyl-reduced alditol acetate 


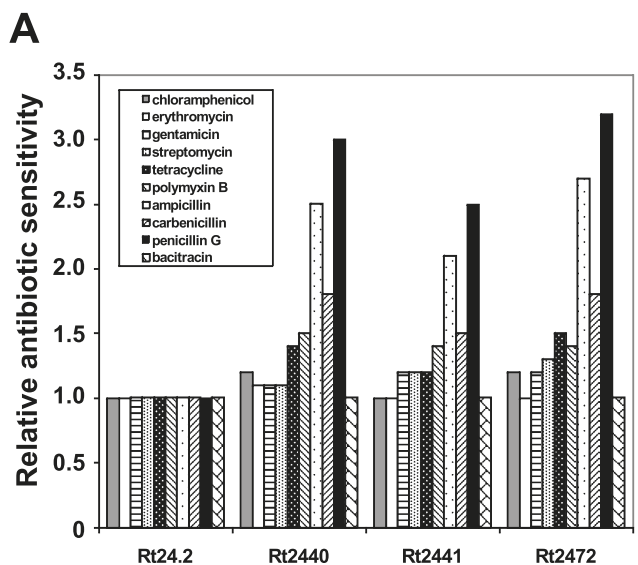

B
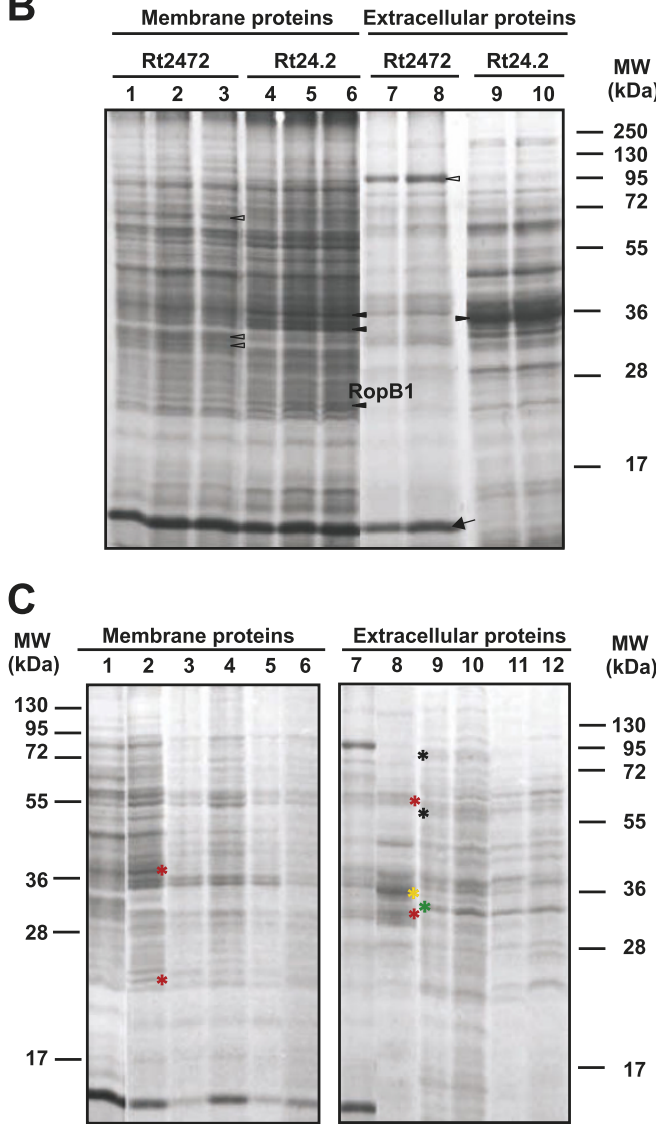

Figure 4 Sensitivity to antibiotics and profiles of membrane and extracellular proteins of $R$. leguminosarum bv. trifolii ros $R$ mutants. Relative sensitivity of the $R$. leguminosarum bv. trifolii ros $R$ mutants to antibiotics, determined by measuring the diameter of growth-inhibition zones (A). The values for the Rt24.2 wild type which were used for result normalization were as follows: chloramphenicol $16.9 \pm 1.5 \mathrm{~mm}$, erythromycin $24.0 \pm 1.5 \mathrm{~mm}$, gentamicin $22.8 \pm 1.8 \mathrm{~mm}$, streptomycin $23.5 \pm 2.0 \mathrm{~mm}$, tetracycline $45.2 \pm 2.2 \mathrm{~mm}$, polymyxin B $5.5 \pm 1.0 \mathrm{~mm}$, ampicillin $9.0 \pm 1.0 \mathrm{~mm}$, carbenicillin $24.5 \pm 2.5 \mathrm{~mm}$, penicillin $\mathrm{G} 3.5 \pm 0.5 \mathrm{~mm}$, bacitracin $14 \pm 2.0 \mathrm{~mm}$. Data shown are means of three replicates. (B) Profiles of membrane and extracellular proteins of the Rt24.2 wild type and
Rt2472 ros $R$ mutant grown in TY medium. The migration positions of molecular mass markers are shown. Lanes: 1, 2, 3 - Rt2472 membrane protein fraction: $3 \mu \mathrm{g}, 6 \mu \mathrm{g}$, and $9 \mu \mathrm{g}$, respectively. Lanes: 4, 5, 6 - Rt24.2 wild type membrane protein fraction: $3 \mu \mathrm{g}$, $6 \mu \mathrm{g}$, and $9 \mu \mathrm{g}$, respectively. Lanes: 7, 8 - Rt2472 extracellular protein fraction isolated from $10 \mathrm{ml}$ and $15 \mathrm{ml}$ culture supernatants, respectively. Lanes: 9, 10 - Rt24.2 extracellular protein fraction isolated from $10 \mathrm{ml}$ and 15 culture supernatants, respectively. The symbols indicate prominent proteins which vary apparently in the amount between the ros $R$ mutant and the wild type: white triangles - proteins up-regulated in Rt2472 mutant, black triangles - proteins of increased amounts in Rt24.2 wild type, arrow - a protein unique to Rt2472 extracellular protein fraction. (C) Membrane and extracellular protein profiles of the wild type and the rosR mutant grown in TY and M1 medium with or without $5 \mu \mathrm{M}$ exudates. Lane: 1- membrane proteins of Rt2472 grown in TY; 2- membrane proteins of Rt24.2 grown in TY; 3- membrane proteins of Rt24.2 grown in $M 1 ; 4$ - membrane proteins of Rt24.2 grown in $M 1$ with $5 \mu \mathrm{M}$ exudates; 5 - membrane proteins of Rt2472 grown in M1; 6 membrane proteins of Rt2472 grown in $\mathrm{M} 1$ with $5 \mu \mathrm{M}$ exudates. In the case of lanes 1 to $6,5 \mu \mathrm{g}$ of proteins were used. Lanes 7 and 8 - extracellular proteins isolated from TY supernatant of Rt2472 and Rt24.2 cultures, respectively; Lanes 9 and 10 - Rt24.2 extracellular proteins isolated from $\mathrm{M} 1$ and $\mathrm{M} 1$ with $5 \mu \mathrm{M}$ exudates supernatants, respectively; Lanes 11 and 12 - Rt2472 extracellular proteins isolated from $\mathrm{M} 1$ and $\mathrm{M} 1$ with $5 \mu \mathrm{M}$ exudates supernatants, respectively. In the case of lines 7 to 12 , proteins from $10 \mathrm{ml}$ culture supernatant were used. The asterisks indicate prominent proteins which vary apparently in the amount between TY and M1 media for the wild type and the rosR mutant: red asterisks - proteins unique to Rt24.2 and Rt2472 strains growing in TY medium, yellow asterisk - a protein unique to the extracellular protein fraction of Rt24.2 isolated from TY supernatant, green asterisk - a protein uniquely present in extracellular protein fractions of Rt24.2 and Rt2472 isolated from M1 supernatants, black asterisks proteins present exclusively in the extracellular protein fraction of Rt24.2 isolated from M1 supernatant.

\section{$R$. leguminosarum ros $R$ mutants are more sensitive to some antibiotics, detergents, and osmotic stresses}

To further characterize the ros $R$ mutants, their sensitivity to a wide range of antibiotics, including those responsible for cell wall and protein synthesis inhibition, was examined (Figure 4A). The Rt2440 and Rt2441 mutants demonstrated similar antibiotic sensitivity profiles. The most remarkable difference in their antibiotic sensitivity in relation to the wild type was a 2.5 - to 3.4-fold increase in susceptibility to beta-lactams, such as carbenicillin, ampicillin, and penicillin G, which impair peptidoglycan synthesis. Also, a slight increase in the sensitivity to polymyxin $B$ (which perturbs the bacterial cell membrane), tetracycline, and chloramphenicol was detected (Figure 4A). The data suggested some changes in the cell envelope structure of the rosR mutants; specifically, the alteration in the LPS and EPS profiles could affect cell wall permeability and, 
consequently, lead to an increase in susceptibility to several antibiotics [33].

To study the possible cell envelope disturbances linked to the ros $R$ mutation, assays of sensitivity to detergents and ethanol were conducted (Table 2). In the presence of SDS, DOC, and ethanol, significant differences in the growth of the rosR mutants in relation to the parental strain were observed, except for Rt2441, for which growth was moderately inhibited by ethanol (Table 2).

The rosR mutants were also significantly more sensitive to hyper-and hypo-osmotic stress than the wild type (Table 2). The mutants achieved only $10-12 \%$ of the growth in TY medium supplemented with $85 \mathrm{mM}$ $\mathrm{NaCl}$ (the highest $\mathrm{NaCl}$ concentration tolerable by the wild type) when compared to a control medium without $\mathrm{NaCl}$. The growth of the rosR mutants was also significantly diminished in relation to the wild type strain in hypo-osmotic GYM medium. The higher sensitivity of the ros $R$ mutants to hypo-osmotic stress might be explained by an increased permeability of their cell membranes allowing greater amounts of neutral polysaccharide (e.g. $\beta$-glucan) to be excreted $[34,35]$. Taken together, rosR mutation seems to affect membrane integrity, resulting in an altered sensitivity to detergents, ethanol, and osmotic stresses.

\section{Changes in membrane and extracellular protein profiles of the ros $R$ mutant in relation to the wild type}

To examine the role of $\operatorname{ros} R$ in the putative membrane leakage, membrane and extracellular proteins of Rt2472 and Rt24.2 grown in TY medium were compared by SDSPAGE (Figure 4B). Some differences in membrane protein profiles were observed, such as two abundant bands with an estimated mass of $\sim 30 \mathrm{kDa}$ and one band of $\sim 63 \mathrm{kDa}$ in Rt2472. In contrast, the amounts of proteins of $\sim 20,34$, and $36 \mathrm{kDa}$ were significantly diminished in this mutant. Based on the literature data, the masses of these three proteins corresponded to mature proteins RopB1 $(20.1 \mathrm{kDa})$, RopA (36 kDA), and RopA1 (38 kDA), which had been identified in R. leguminosarum [36-38].

An extracellular protein profile of $R$. leguminosarum bv. trifolii 24.2 was very similar to that of $R$. leguminosarum bv. viciae 3841 [22]. In extracelullar protein profiles of Rt24.2 and Rt2472, besides several bands common to both supernatants, a protein of $\sim 13 \mathrm{kDa}$ was uniquely present, and a protein of $\sim 83 \mathrm{kDa}$ was significantly more abundant in the ros $R$ mutant supernatant (Figure 4B). On the other hand, the amounts of proteins of about $36 \mathrm{kDa}$ were drastic diminished in the Rt2472 culture supernatant. The differences in protein patterns between the wild type and the rosR mutant indicated that some additional proteins were being secreted from the cells, perhaps as a result of unspecific membrane leakage, possibly due to changes in membrane permeability triggered by the mutation.

To study the effect of clover root exudates on the protein profiles of Rt2472 and Rt24.2, the strains were cultured in M1 medium with or without $5 \mu \mathrm{M}$ exudates, and membrane and extracellular proteins were isolated (Figure 4C). It was observed that this culture medium influenced both extracellular and membrane proteins when compared to TY grown cultures. Most apparent differences were found for secreted proteins. For Rt2472 and Rt24.2, proteins of about $60 \mathrm{kDa}$ and $31 \mathrm{kDa}$ (for Rt24.2 also a protein of $\sim 35 \mathrm{kDa}$ ) present in TY supernatants were absent when these strains grew in M1. On the other hand, additional proteins were present in M1 supernatants. Some differences between the rosR mutant and the wild type were detected in the proteins from M1 supernatants. However, the effect of root exudates on extracellular protein profiles was not noticeable.

In membrane proteins, a major difference concerned two proteins of $\sim 38 \mathrm{kDa}$ and $\sim 20 \mathrm{kDa}$, which were present in both strains grown in TY medium but were missing in the M1 grown cultures (Figure 4C). No visible differences in protein profiles were detected between these two strains grown in M1 and in the presence of root exudates.

The purity of the membrane and the extracellular protein fractions isolated from Rt2472 and Rt24.2 was assayed by Western blotting with anti-PssB and antiPssN antisera specific to R. leguminosarum (see additional file 1: Figure S1). PssB, previously described as cytoplasmic inositol monophosphatase present in two

Table 2 Sensitivity of $R$. leguminosarum bv. trifolii ros $R$ mutants to detergents, ethanol, and osmotic stress.

\begin{tabular}{|c|c|c|c|c|c|}
\hline \multirow[t]{2}{*}{ Strain } & \multicolumn{3}{|c|}{ Minimal inhibitory concentration } & \multirow{2}{*}{$\begin{array}{c}\text { Hyperosmotic } \\
\text { stress }(\%)^{*}\end{array}$} & \multirow{2}{*}{$\begin{array}{c}\text { Hypo-osmotic } \\
\text { stress }(\%)^{*}\end{array}$} \\
\hline & SDS (\% w/v) & DOC (\% w/v) & Ethanol (\%v/v) & & \\
\hline Rt24.2 & $0.05 \pm 0.005$ & $0.10 \pm 0.005$ & $4.5 \pm 0.28$ & 77.1 & 51.6 \\
\hline Rt2441 & $0.02 \pm 0.002 \dagger$ & $0.030 \pm 0.003 \dagger$ & $3.0 \pm 0.28$ & $11.9+$ & $15.2+$ \\
\hline Rt2472 & $0.015 \pm 0.002 \dagger$ & $0.025 \pm 0.002 \dagger$ & $2.6 \pm 0.28+$ & $10.4 \dagger$ & $13.3+$ \\
\hline
\end{tabular}

* - Strains were grown in TY supplemented with $85 \mathrm{mM} \mathrm{NaCl}$ (hyperosmotic) or GYM medium (hypo-osmotic) supplemented with Dilworth's vitamins for 2 days, and the growth was compared with that of strains grown in TY medium. $\mathrm{OD}_{600}$ values were measured. Percentage growth values are the mean and SD from three independent trials.

† Difference between the wild type and the ros $R$ mutants is statistically significant at $\mathrm{P}<0.05$ (Student's $t$ test). 
forms of 32 and $29.5 \mathrm{kDa}$, was used as a marker of cytoplasmic proteins [39], and PssN lipoprotein (43-kDa) as a marker of membrane proteins [40]. No substantial contamination of membrane and extracellular protein fractions by this cytoplasmic protein was detected (Figure S1A). For PssN, besides a strong signal in membrane fractions, residual signals were also detected in the cytoplasmic fraction and extracellular proteins of Rt24.2 grown in M1 (Figure S1B). This finding was in agreement with the previously described detection of low amounts of PssN in the culture supernatant [40].

To identify the individual membrane and extracellular proteins of the ros $R$ mutant that differed in abundance from those of the wild type strain, we submitted them to Edman degradation sequencing. Unfortunately, possibly due to blocked $\mathrm{N}$-terminus of the proteins, only the protein of $20 \mathrm{kDa}$ that was less abundant in the ros $R$ mutant TY medium membrane fraction, was identified by this method. The sequence of the $15 \mathrm{~N}$-terminal amino acids (ADAVDQVPEAPVAQD) showed 100\% identity to the 25-39 aa region of the OmpA-like protein of $R$. leguminosarum bv. trifolii WSM1325 (C6AU25), the outer membrane protein RopB1 of $R$. etli CFN42 (Q2KA52), and RopB1 of $R$. etli CIAT652 (B3PV86).

\section{$R$. leguminosarum bv. trifolii rosR mutants are altered in motility and biofilm formation}

The effect of rosR mutation on the motility of $R$. leguminosarum was assessed (Figure 5) and a very strong inhibition of motility in the studied mutant strains was observed. The swimming zones were from 2- (Rt2441) to 2.5-fold smaller (Rt2440 and Rt2472) than for Rt24.2 wild type following growth on M1 semisolid medium for 72 h. The Rt5819 strain, entirely deficient in EPS synthesis due to a mutation in $p s s A$ encoding a glucosyl-IP-transferase, showed a similar motility-deficient phenotype. Complementation of the $\operatorname{ros} R$ mutation with pRC24 carrying wild type $\operatorname{ros} R$ fully restored the swimming radius of $\mathrm{Rt} 2472$. The results demonstrate that the $\operatorname{ros} R$ mutation negatively affected mutant motility.

To determine whether the $\operatorname{ros} R$ mutation affected biofilm formation, growth of the wild type and the ros $R$ mutants was analyzed in M1 in a microtiter plate assay. This medium was used in an attempt to reflect soil conditions where nutrients are usually scarce. In the assay, the mass of biofilm formed by the ros $R$ mutants, as measured by crystal violet binding, was substantially lower, i.e., 37\% (Rt2440) and 45\% (Rt2441), respectively, in relation to the wild type (Figure 6). The $R$. leguminosarum bv. trifolii pssA mutant, included in this assay, formed only $18 \%$ of the wild type biofilm, which confirms the earlier observations on biofilm formation by an $R$. leguminosarum bv. viciae pssA mutant [14].

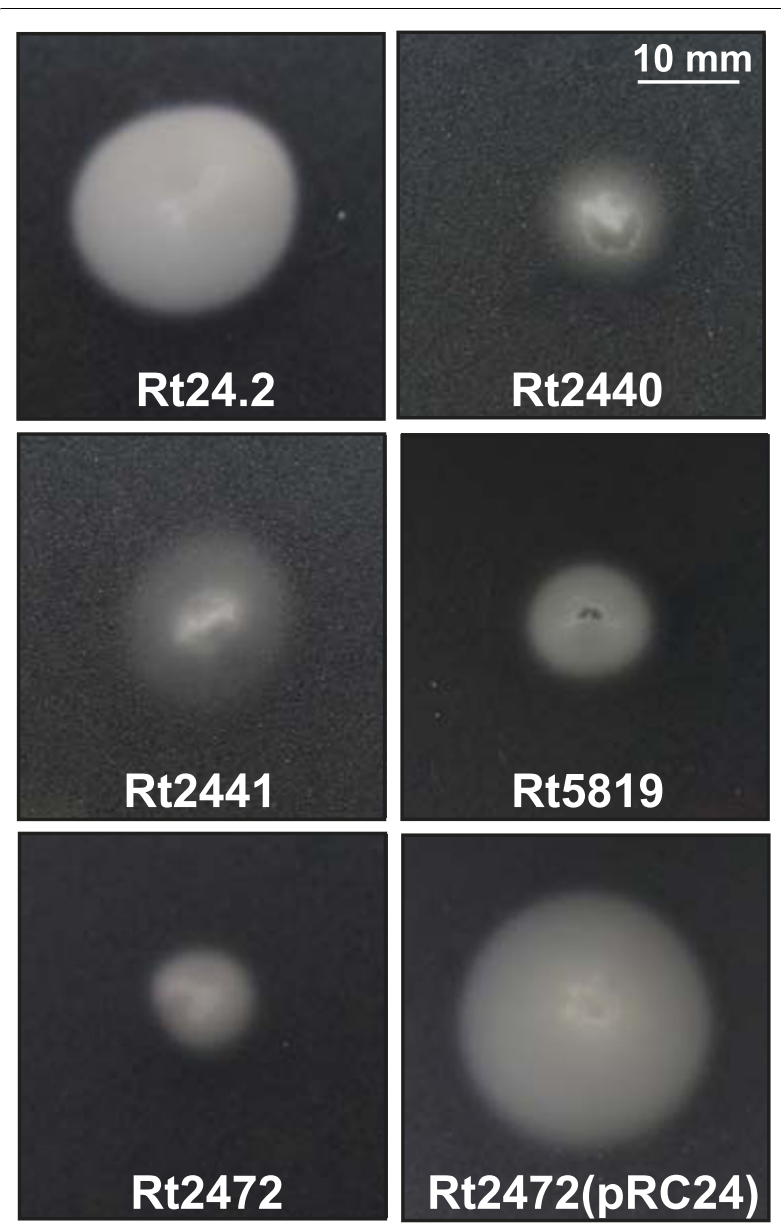

Figure 5 Motility of $R$. leguminosarum bv. trifolii 24.2 wild type and its derivatives after 3 -day incubation at $28^{\circ} \mathrm{C}$ on $0.3 \% \mathrm{M} 1$ agar plates.

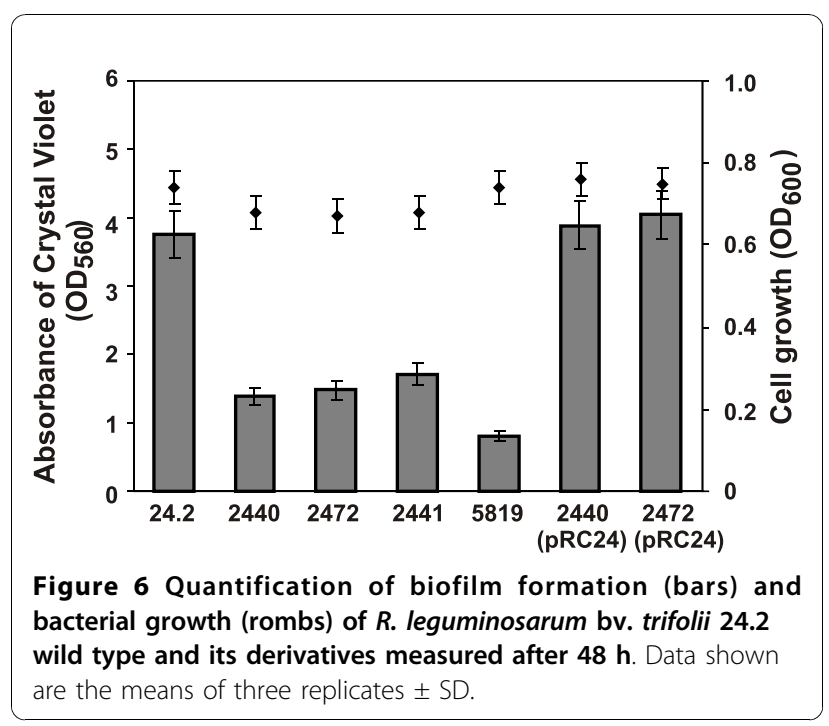


Complementation of rosR mutation with pRC24 restored biofilm development to the wild type levels (Figure 6).

The rosR mutant (Rt2472) and the wild type strain were chosen to examine the organization and viability of $R$. leguminosarum bv. trifolii cells in biofilm. The organization of adherent bacteria on plastic surfaces differed substantially between the wild type and the mutant (Figure 7). After four days of growth, the Rt24.2 formed a typical mature biofilm with water channels. The parameters describing the biofilms formed by the wild type and the rosR mutant are listed in Table 3. The ros $R$ mutant developed a biofilm which was nearly two times thinner than the wild type's, and which was unorganized and impaired in maturation, with a significantly lower number of viable cells. Complementation of the ros $R$ mutant with pRC24 restored the wild type phenotype, and Rt 2472 (pRC24) formed a mature biofilm with highly viable bacteria, comparable to the wild type (Figure 7).

\section{Effect of clover root exudates on growth of rosR mutants and EPS production}

The increased sensitivity of the rosR mutants to surface active compounds (Table 2) and some antibiotics, most probably caused by changes in membrane protein profiles (Figure 4), inclined us to assess the effect of clover root exudates on growth of the rosR mutants. The strains were grown in M1 medium supplemented with $5 \mu \mathrm{M}$ root exudates, and aliquots of the cultures were plated in dilutions on 79CA medium. Clover root exudates slightly enhanced the growth of the Rt24.2 wild type (Figure 8A). The rosR mutants (Rt2472 and Rt2441) grew significantly slower than the wild type in M1 medium and were more sensitive to the root exudates (Figure 8B-C). In the presence of the exudates, Rt24.2 produced a significantly increased amount of EPS, whereas the level of EPS produced by the $\operatorname{ros} R$ mutants was increased only slightly (Figure 8D).

\section{Phenotype analysis of a ros $R$ mutant using Biolog tests}

In several experiments, we noticed that the $\operatorname{ros} R$ mutants grew slower than the wild type both in liquid and solid media, suggesting changes in their metabolic capabilities. In an attempt to define the phenotype profile of the rosR mutant (Rt2472) in relation to the wild type strain, the PM system (Biolog) was used [41]. PM1, PM2A, PM3B, and PM4A plates were chosen, allowing for examination of the utilization of 190 different carbon sources and 95 nitrogen, 59 phosphorus, and 35 sulfur sources. In addition, PM9 plates were used to test the growth under various stress conditions.

In general, the ros $R$ mutant utilized fewer energy sources and was significantly more sensitive to the majority of the tested osmolytes than the wild type
(Figure 9A). The most visible differences were observed in utilization of carbon and nitrogen sources (Figure 9B). Mutant Rt2472 utilized several carbon and nitrogen sources two to four times less efficiently than the parental strain. In contrast, utilization of some amino acids, pyruvic acid, and 2-aminoethanol (PM2A) by the ros $R$ mutant was considerably higher than for the wild type. Moreover, nine of the tested sugar sources and twelve of the nitrogen sources were not utilized by the ros $R$ mutant (PM1, PM2A, and PM3B) (Figure 9B).

The phenotype of the Rt2472 mutant did not differ essentially from the wild type with regard to utilization of phosphorus sources (PM4B) except that they were metabolized less effectively. It is worth noting that the Rt2472 significantly better utilized sulfur sources, such as L-cysteine, L-cysteic acid, and S-methyl-L-cysteine (PM4A), than the wild type. This suggests derepression of the sulfur metabolic pathway in the rosR mutant background.

PM9 microplates were used to determine the sensitivity of the rosR mutant to several osmolytes. We observed a significant increase in $\operatorname{ros} R$ mutant sensitivity in the presence of $\mathrm{NaCl}, \mathrm{Na}_{3} \mathrm{PO}_{4},\left(\mathrm{NH}_{4}\right)_{2} \mathrm{SO}_{4}$, and $\mathrm{NaNO}_{3}$. In contrast to the wild type, Rt2472 did not survive in $100 \mathrm{mM} \mathrm{Na} \mathrm{PO}_{4}, 50 \mathrm{mM}\left(\mathrm{NH}_{4}\right)_{2} \mathrm{SO}_{4}, 60 \mathrm{mM}$ $\mathrm{NaNO}_{3}$, and $10 \mathrm{mM} \mathrm{NaNO}$ (Figure 9B).

In summary, the rosR mutant was impaired in its ability to utilize several compounds and exhibited an increased sensitivity to some osmolytes, suggesting a role of RosR protein in the control of many essential metabolic processes.

\section{Effect of rosR mutation on root hair attachment and infection}

The ros $R$ mutants formed significantly fewer nodules on clover roots than the wild type strain and their appearance was delayed (Table 1). This might indicate a failure in the first stages of mutant strain's interaction with the roots. To visualize root hair attachment of rhizobia and their ability to grow on the root surface and infect root hairs, the Rt24.2 and Rt2472 strains harbouring plasmid pHC60 with constitutively expressed $g f p$ [42] were used. Clover seedlings inoculated with the bacteria on Fåhraeus medium-covered microscope slides were observed in the course of time. After the first $90 \mathrm{~min}$, single Rt24.2 cells were visible on the surface of root hairs (Figure 10A). After $24 \mathrm{~h}$, attachment of numerous Rt24.2 cells to root hairs was seen. Bacteria were located mainly on root hair tops, forming caps and rhizobial clouds (Figure 10B). In the zone of growing root hairs, the majority of the root hairs were coated with Rt24.2 cells (Figure 10C). After 6 days post infection (dpi), infection threads inside some of the root hairs were initiated or already extended and reached root epidermal cells (Figure 10D). In contrast, Rt2472 cells were seen 


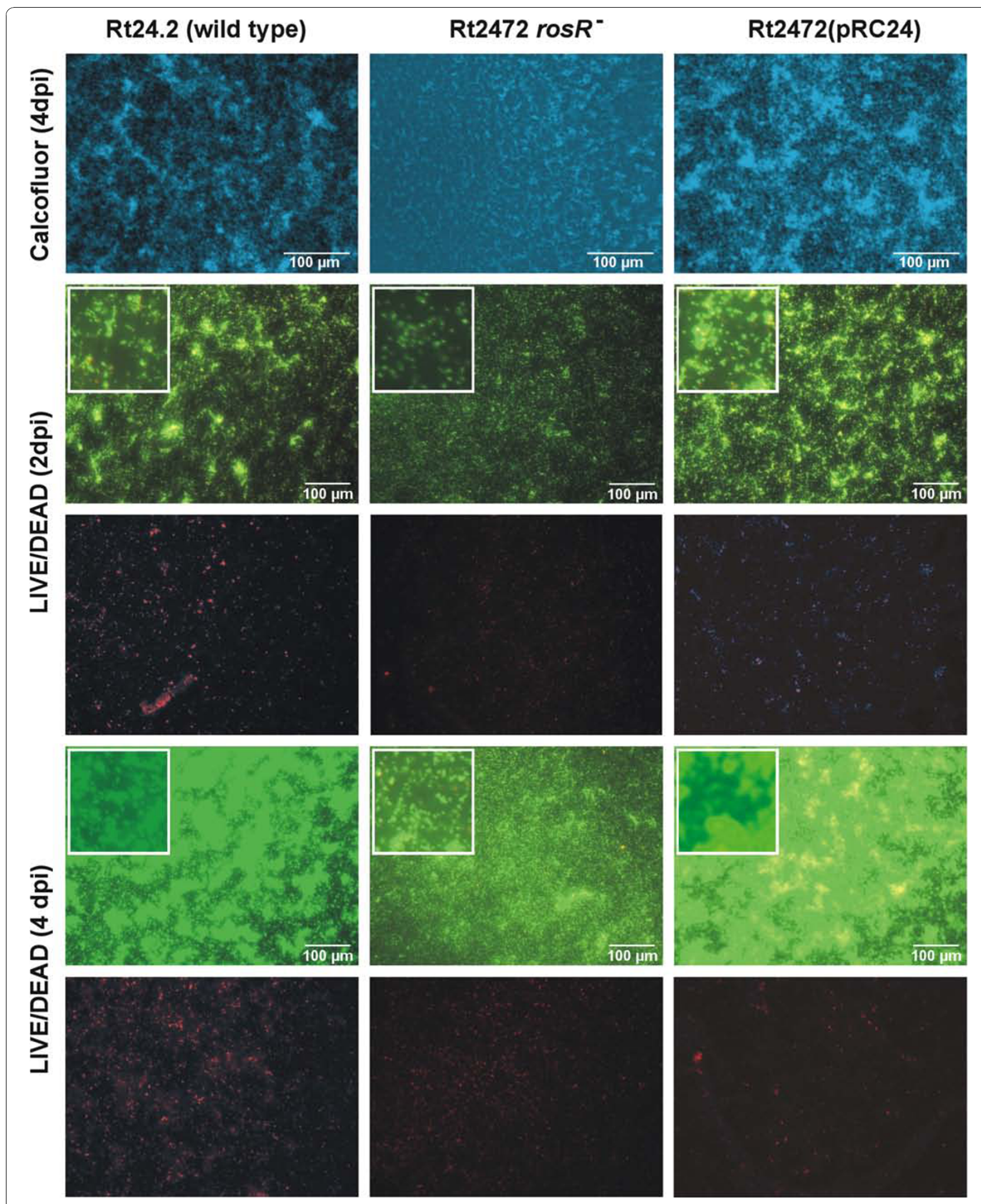

Figure 7 Developing stages of biofilm formation in R. leguminosarum bv. trifolii wild type 24.2, rosR mutant Rt2472 and Rt2472 (pRC24) strains observed after 2 and 4 days. The rosR mutant Rt2472 did not form typical biofilm after 4 days and was restored to the wild type phenotype after introduction of the rosR gene cloned on pRC24 plasmid. Top panel shows 4 dpi biofilms stained with Calcofluor, and the remaining panels show horizontal projected images from 2 and 4 dpi biofilms, with live (Syto-9, green fluorescence) and dead (propidium iodide, red fluorescence) cells. The insets show details of individual stages of biofilm formation. 
Table 3 The parameters of biofilms formed by the $R$. leguminosarum bv. trifolii wild type and Rt2472 ros $R$ mutant.

\begin{tabular}{lccccc}
\hline Strain & $\begin{array}{c}\text { Ratio of live/dead } \\
\text { cells }\end{array}$ & $\begin{array}{c}\text { Depth of } \\
\text { biofilm }(\boldsymbol{\mu m})\end{array}$ & $\begin{array}{c}\text { Area covered by } \\
\text { biofilm }(\%)\end{array}$ & $\begin{array}{c}\text { Fractal dimension } \\
(\text { scalar units) }\end{array}$ & $\begin{array}{c}\text { Outline }\left(\times \mathbf{1 0}^{\mathbf{3}}\right) \\
(\boldsymbol{\mu m})\end{array}$ \\
\hline Rt24.2 & $51.06 \pm 6.12$ & $47.33 \pm 1.15$ & $87.57 \pm 6.36$ & $1.425 \pm 0.05$ & $109.25 \pm 5.9$ \\
Rt2472 & $27.53 \pm 4.57 \dagger$ & $25.66 \pm 1.52 \dagger$ & $50.17 \pm 5.08 \dagger$ & $1.325 \pm 0.14$ & $69.71 \pm 1.2 \dagger$ \\
Rt2472(pRC24) & $71.86 \pm 3.07$ & $54.26 \pm 3.94$ & $88.82 \pm 8.78$ & $1.417 \pm 0.06$ & $113.57 \pm 10.8$ \\
\hline
\end{tabular}

† Difference between the wild type and the ros $R$ mutant is statistically significant at $\mathrm{P}<0.05$ (Student's $t$ test).

on the root surface but were attached to the root hairs only sporadically demonstrating a much weaker attachment ability (Figure 10E). The caps formed by rosR cells on the top of root hairs were detected very rarely (Figure 10F). In addition, several root hairs had an atypical, expanded shape resembling ginger roots (Figure $10 G)$ in contrast to the typical curled root hairs in clover inoculated with the wild type. In the case of ros $R$ mutant-inoculated plants, infection threads inside root hairs were observed sporadically, and their elongation was frequently interrupted (Figure 10H).

To quantitatively determine the attachment ability to the surface of clover roots, Rt24.2 wild type, Rt2472 and Rt2441 rosR mutants, and their derivatives bearing plasmid pRC24 were incubated with clover roots for $0.5 \mathrm{~h}$ and 48 $h$. The wild type cells showed a high attachment ability to the root surface (Figure 10I). In contrast, the number of Rt2472 and Rt2441 cells attached to roots during $0.5 \mathrm{~h}$ was drastically lower (3.6\% and $4.7 \%$ of the wild type, respectively). After $48 \mathrm{~h}$, the rosR mutant cells were still considerably less numerous than Rt24.2 (14.6\% for Rt2472 and $16.5 \%$ for Rt2441). These assays confirmed that rosR mutation affects the first step of the infection process, i.e., bacterial adhesion to root hairs (Figure 10I).

To study the further stages of clover infection, seedlings were inoculated with Rt24.2 and Rt2472 tagged with $g f p$ and observed under a light microscope during a 10-day experiment. The following were quantified: (i) tightly curled root hairs containing trapped rhizobia, (ii) initiated (immature or aborted) infection threads, and (iii) infection threads which successfully entered the root cortex of clover. As was shown in Figure 10J, wild type bacteria effectively colonized curled root hairs, and the first initiated infection threads were observed after 4 dpi. Extended infection threads were formed from almost all colonized root hairs, giving, on average, 5.6 successful infections per plant after 10 days. The ros $R$ mutant exhibited notable differences in infection thread formation. Rt2472 cells colonized root hairs very rarely and with a delay in comparison to the wild type. As a consequence, the initiation of infection threads was observed only occasionally and a great majority of the infection threads was not properly extended and did not reach root cortical cells (Figure 10J).

\section{Discussion}

In this paper, we present data showing that RosR of $R$. leguminosarum bv. trifolii 24.2 , besides its role in transcriptional regulation of EPS synthesis, is required for successful interaction with clover plants, stress tolerance, motility, and biofilm formation. Both the rosR mutants (Rt2440 and Rt2472) described earlier [23,30] and the newly isolated Rt2441, bearing a genomic wild type rosR with the regulatory region in addition to the mutated rosR copy, displayed pleiotropic phenotypes. Pleiotropy of the ros $R$ mutants was fully restored in complementation tests using a low-copy plasmid carrying rosR. Interestingly, the Rt2441 mutant showed a negative dominant effect on EPS production, which confirmed the regulatory role of RosR in EPS synthesis. This phenomenon could be explained, to some extent, by negative autoregulation of $\operatorname{ros} R$ expression [23], which may be strengthened by the presence of more RosR-boxes binding RosR (Figure 2). As a result, the diminished amount of functional RosR might be insufficient for positive regulation of EPS production. The negative dominance could be overcome by introducing additional copies of rosR in the complementation experiments (Table 1, Figure 2). A similar dominant-negative effect of rosAR mutation in $A$. radiobacter had been described by Brightwell et al. [43]. The introduction of rosAR lacking the 3 " terminus on a plasmid into a wild type strain resulted in non-mucoid transconjugants.

All the $\operatorname{ros} R$ mutants were considerably impaired in both the level of EPS production and the rate of its polymerization. They produced three times less EPS which was also slightly changed in non-carbohydrate modification and the level of polymerization. In addition, PS part of Rt2440 LPS showed quantitative differences in the sugar composition (mainly in 6-deoxysugars ratio) in comparison to the wild type PS.

Like most $R$. leguminosarum bv. trifolii mutants deficient in surface polysaccharide production [6], the ros $R$ mutants elicited nodules in which rhizobia did not fix nitrogen. These mutants were also not competitive in relation to the wild type. Rt2472 and Rt2441, even when present in the inoculum in 1000-fold excess to the wild type, occupied only about $10 \%$ of the clover nodules. An $R$. etli ros $R$ mutant formed colonies with an altered morphology, but retained the ability to elicit nitrogen- 


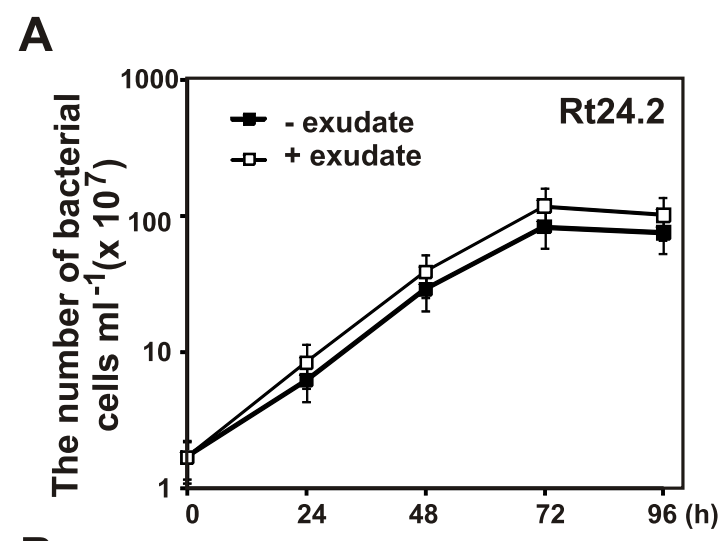

B

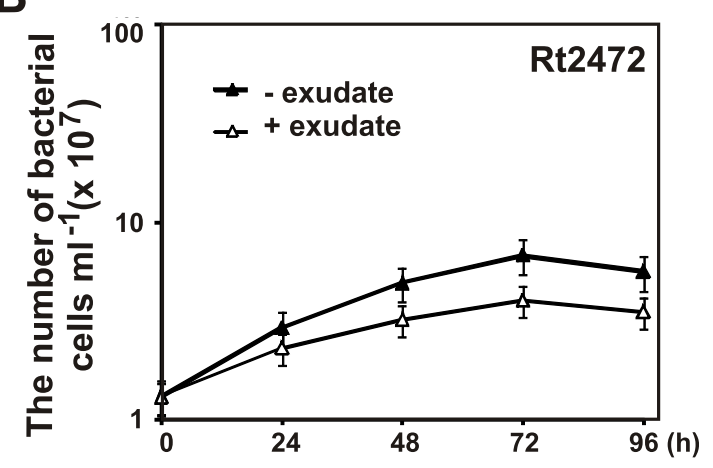

C

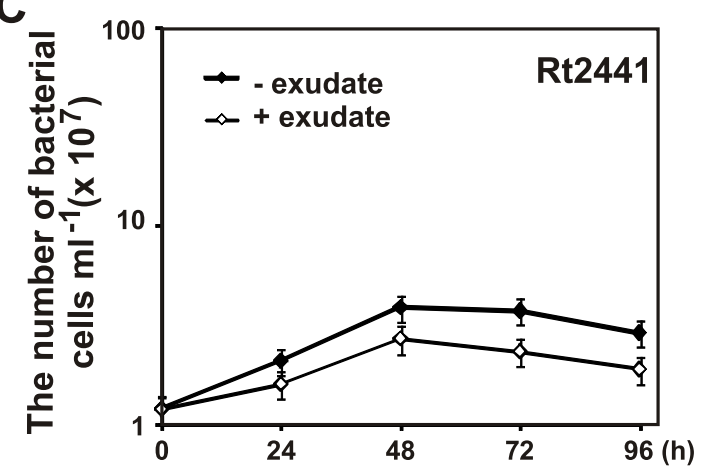

D

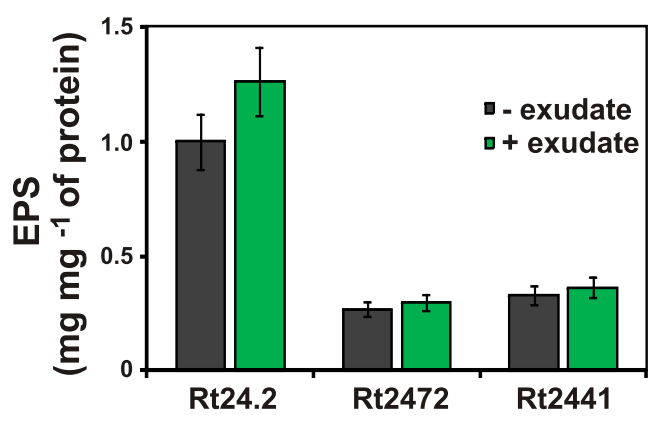

Figure 8 The effect of clover root exudates on the growth of Rt24.2 wild type (A), and Rt2472 (B) and Rt2441 (C) rosR mutants. (D) The effect of clover root exudates on the EPS production by the wild type and the ros $R$ mutants. Data shown are the means of three replicates \pm SD. fixing nodules on Phaseolus vulgaris, which forms determinate-type nodules [24]. Nevertheless, the nodulation competitiveness of that rosR mutant was greatly reduced and, for this reason, $\operatorname{ros} R$ was considered a determinant of $R$. etli competitiveness.

One of the most striking effects of ros $R$ mutation in $R$. leguminosarum bv. trifolii is the drastic decrease in attachment to root hairs and growth on the root surface. In contrast to the wild type strain, ros $R$ mutant cells only sporadically formed caps on the top of root hairs, and, consequently, infection threads were initiated rarely, and the majority of them were aborted. Recently, a similar effect of $R$. leguminosarum pss $A$ mutation has been described: the mutant was defective in attachment and biofilm formation both in vitro and on root hairs [18]. An R. leguminosarum gmsA mutant, which did not produce glucomannan, demonstrated a very similar symbiotic phenotype to the rosR mutant Rt2472. It was defective in attachment and biofilm formation on root hairs and was strongly outcompeted by the wild type in mixed inoculations, showing that glucomannan is critical for competitive nodulation [18]. In the case of $R$. leguminosarum cellulose synthesis mutant (celA) only individual cells attached to root hairs, but caps were not formed [18]. Other EPS-deficient mutants such as R. leguminosarum (pssD) and S. meliloti (exoY) were defective in infection thread formation $[42,44]$. In S. meliloti, an exoH mutant lacking the succinyl modification in succinoglycan and an exo $Z$ mutant producing this heteropolymer without the acetyl modification exhibited a reduced efficiency in the initiation and elongation of infection threads [42]. S. meliloti exoR and exoS mutants overproducing EPS I demonstrated a marked reduction in the biosynthesis of flagella resulting in a loss of the ability of the cells to swarm and swim and had a significantly reduced efficiency of root hair colonization [45]. In conclusion, defective attachment and infection thread formation in the first stages of symbiosis seem to be common features of rhizobial mutants which produce altered surface polysaccharides and infect plants which form indeterminate-type nodules.

The pleiotropic effect of $\operatorname{ros} R$ mutation was also expressed as an increased sensitivity to detergents, hyper- and hypo-osmotic stress, and antibiotics from the beta-lactam group which affect peptidoglycan synthesis. The Rt2472 mutant also exhibited an increased sensitivity to several osmolytes indicating that RosR is engaged in the regulation of many essential cell processes. These changes in the phenotype indicated a direct or indirect effect of rosR mutation, which, presumably, affects membrane integrity or causes outer membrane instability. This was partially evidenced by SDS-PAGE of membrane and secreted proteins isolated from the wild type and rosR mutant (Rt2472). We 
A

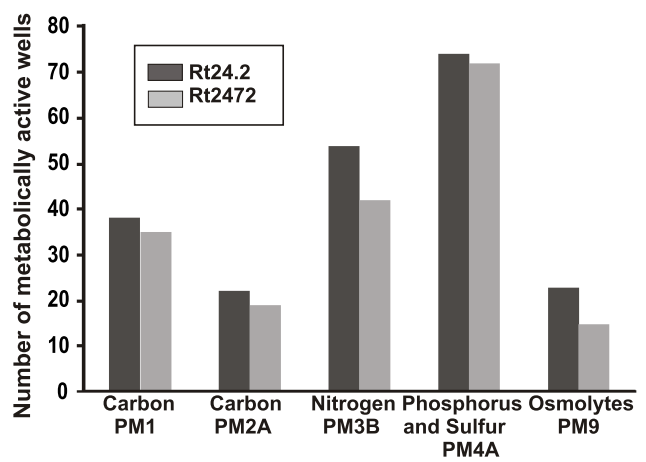

B

PM1

24.22472

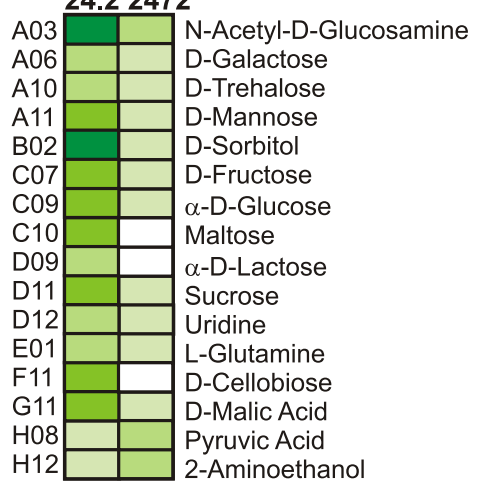

24.22472

PM2A

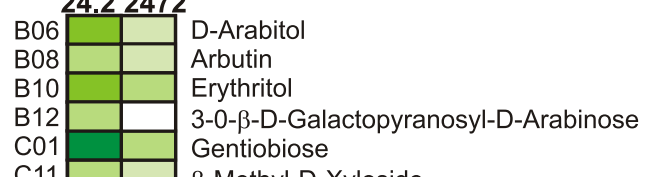

C11 $\square$-Methyl-D-Xyloside

C12 Palatinose

D01 D-Rafinose

D04 L-Sorbose

D07 1 Turanose

G02 L-Alaninamide

G06 $\longrightarrow$ L-Histidine

G10 $\longrightarrow$ L-Leucine

L-Lysine

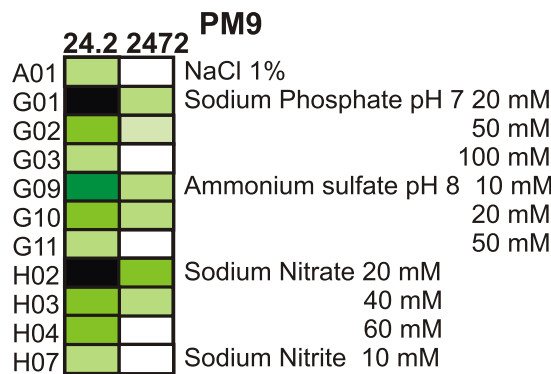

PM3B

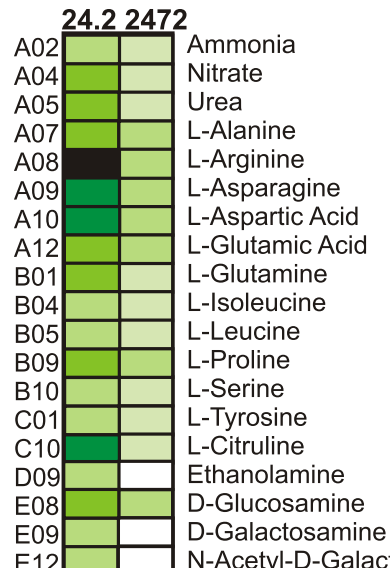

\begin{tabular}{l|l} 
E12 & \\
F04 & N-Acetyl-D-Galactosamine \\
Cytidine
\end{tabular}

F05 $\square$ Cytosine

F06 Guanine

F07 $\quad$ Guanosine

F10 Uracil

F11 $\square$ Uridine

F12 $\square$ Inosine

G03 Uric Acid

$\mathrm{H} 01 \longrightarrow$ Ala-Asp

H02 Ala-GIn

$\mathrm{HO} \longrightarrow$ Ala-Glu

H05 $\longrightarrow$ Ala-His

H07 Ala-Thr

$\mathrm{H} 08$ Gly-Asn

H09 $\longrightarrow$ Gly-GIn

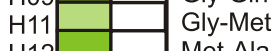

H12 $\square$ Met-Ala

\section{PM4A}

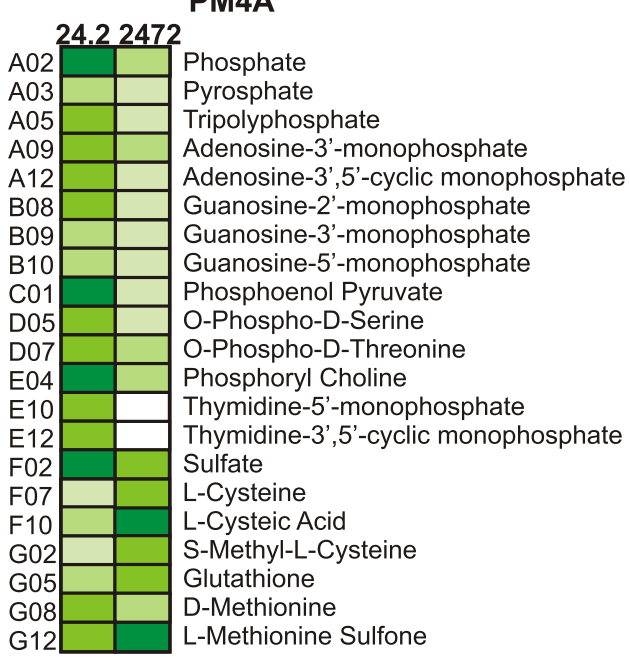

Figure 9 A quantitative and qualitative comparison of the carbon, nitrogen, phosphorus, and sulfur sources metabolized by the ros $R$ mutant and the wild type strain. (A) The number of metabolized compounds by the ros $R$ mutant Rt2472. (B) Metabolic differences between the wild type Rt24.2 and Rt2472 mutant in PMs. The following color code for the level of utilization of metabolic sources is used: $\mathrm{OD}_{600}<0.1$, very light green; $\mathrm{OD}_{600}$ between 0.1 and 0.2 , light green; $\mathrm{OD}_{600}$ between 0.2 and 0.3 , medium green; $\mathrm{OD}_{600}$ between 0.3 and 0.4 , dark green; $\mathrm{OD}_{600}>0.4$, black; unutilized metabolites are denoted by white boxes. Data shown are the means of two replicate experiments. 


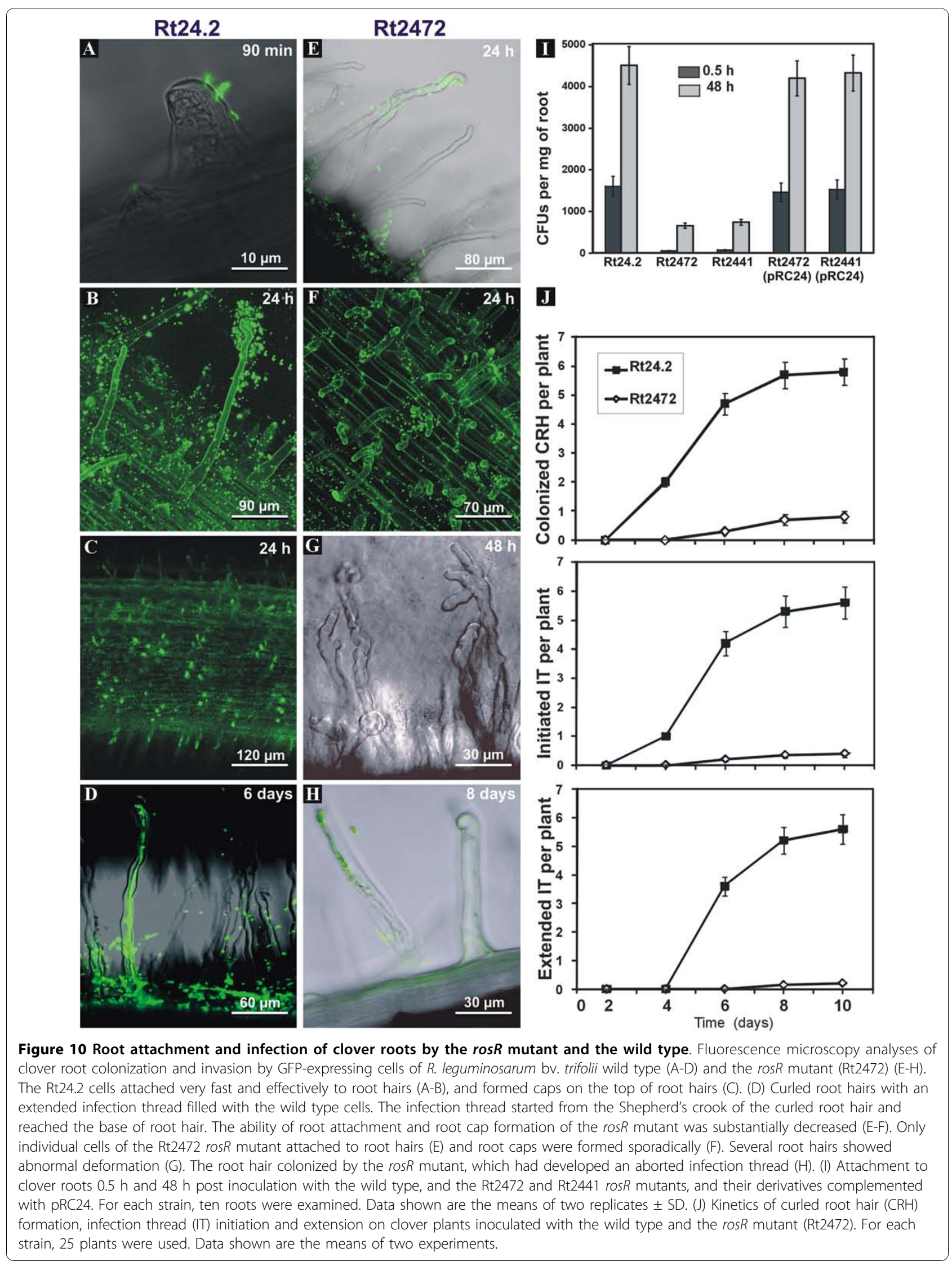


observed some differences in the protein profiles of both strains, especially when they were cultured on TY rich medium. Out of the several membrane proteins whose concentrations were significantly decreased in the $\operatorname{ros} R$ mutant, three proteins corresponded to outer membrane proteins RopB1 (20.1 kDa), RopA (36 kDA), and RopA1 (38 kDA) of $R$. leguminosarum [36-38]. Among them, the $20 \mathrm{kDa}$ protein was identified as OmpA-like RopB1. The diminished amount of this protein in the ros $R$ mutant could influence its membrane integrity and sensitivity to surface-active compounds and some antibiotics. Several classes of outer membrane proteins (OMPs) of $R$. leguminosarum bv. viciae strain 248 had been described as antigens, and the level of some of them significantly decreased during bacteroid differentiation [36-38]. Recently, a gene family of OMPs (ropB, $\operatorname{rop} B 2$, and ropB3) in $R$. leguminosarum bv. viciae VF39SM has been described [46]. A ropB mutant was characterized by an increased sensitivity to detergents, hydrophobic antibiotics, and weak organic acids, which suggested a role of RopB in outer membrane stability [46].

Extracellular protein profile of $R$. leguminosarum bv. trifolii 24.2 wild type growing in TY was very similar to that of R. leguminosarum bv. viciae 3841 described by Krehenbrink and Downie [22]. Significant differences between TY supernatant protein profiles of the Rt24.2 and the Rt2472 were observed. The main difference was essentially diminished the amount of proteins of about $35 \mathrm{kDa}$ in the ros $R$ mutant. In the supernatant of $R$. leguminosarum bv. viciae 3841, proteins of similar molecular masses (35.6-kDa Leu/Ile/Val-binding protein, 34.1-kDa flagellin, and 34.1-kDa basic membrane lipoprotein) were identified.

Moreover, extracellular proteins of the wild type and the ros $R$ mutant differed depending on growth in complex (TY) or minimal (M1) media, similarly to proteins secreted by the $R$. leguminosarum bv. viciae 3841 prsD mutant [22].

R. leguminosarum bv. viciae 3841 , an LPS mutant (fabF2/F1) lacking the very long chain fatty acid $\left(27 \mathrm{OHC}_{28: 0}\right)$ component of lipid $\mathrm{A}$, displayed an increased sensitivity to membrane stressors and an increase in the secretion of neutral surface polysaccharides, namely, periplasmic cyclic $\beta$-(1,2)-glucans [35]. The production of these compounds is associated with hypoosmotic stress tolerance in rhizobia [47]. The higher sensitivity of the ros $R$ mutants to hypo-osmotic stress might be explained by increased permeability of their cell envelopes, which could allow excretion of greater amounts of neutral polysaccharides.

Recently, several other osmotically unstable rhizobial mutants have been described, among them salt-sensitive mutants of S. meliloti, some of them significantly affected in competing against the wild type for nodule occupancy [48]. Mutation in S. meliloti regulatory gene $n e s R$ affected competition for nodulation, adaptation to high osmolarity, and nutrient starvation [49]. Also, genes encoding trehalose biosynthesis pathways and potassium uptake systems were found to be important for S. meliloti growth in hyperosmotic medium [50,51].

$R$. leguminosarum bv. trifolii rosR mutants deficient in EPS production grew considerably slower than the wild type on minimal medium. Using the Biolog system, we established that the rosR mutant revealed differences in utilization of carbon and nitrogen sources in relation to the wild type. Similarly, phenotypic analysis of S. meliloti exoS and chvI null mutants demonstrated that ExoS/ChvI regulatory system not only controls succinoglycan (EPS I) and galactoglucan (EPS II) synthesis but is also required for growth on over 21 different carbon sources [52]. The $c h v I$ mutant exhibited several pleiotropic effects: failed to grow on complex medium, had an altered LPS profile, exhibited lower tolerance to acidic conditions, was hypermotile, and synthesized significantly less poly-3-hydroxybutyrate than wild type, indicating that $\mathrm{ChvI}$ is engaged in regulatory networks involving the cell envelope and metabolism [53].

In several studies, a connection between the production of bacterial polysaccharides and motility has been established. Both $R$. leguminosarum bv. trifolii rosR mutants and the pssA mutant deficient in EPS production exhibited a significant decrease in motility. S. meliloti MucR protein that simultaneously acts as a transcriptional repressor of galactoglucan synthesis and an activator of succinoglycan synthesis $[25,54]$ inhibits the expression of rem encoding an activator of the expression of such genes as flaF and flgG [55]. Other regulatory proteins, such as the ExpR/Sin quorum system, are additionally engaged in the regulation of $S$. meliloti motility $[56,57]$. A non-motile phenotype has also been described for $n d v A$ and $n d v B$ mutants defective in the synthesis of $\beta$-(1,2)-glucans under hypoosmotic conditions $[58,59]$. Alterations in the LPS structure often cause motility-related defects $[60,61]$. The $R$. leguminosarum bv. viciae 3841 LPS mutant mentioned earlier was impaired in motility and biofilm formation. In this mutant, the motility genes flaA, $m c p C$, $m c p D$, vis $N$, and rem were significantly down regulated when compared with the wild type [35].

The $R$. leguminosarum bv. trifolii ros $R$ mutants formed significantly reduced amounts of biofilm, which was altered in structure and maturation and contained more dead cells in comparison to the wild type. The Rt24.2 pssA mutant formed smaller amounts of biofilm in comparison to the ros $R$ mutants, which confirms the important role of this polymer in biofilm development. Similarly, R. leguminosarum bv. viciae pssA mutant was unable to develop microcolonies and more complex biofilm structures $[14,18]$. The presence of a RosR-box motif in the promoter 
region of $R$. leguminosarum bv. trifolii pss $A$ and the significantly lower expression of pssA-lacZ fusion in the rosR mutant than in the wild type indicate positive regulation of this gene by RosR $[23,62]$. In S. meliloti, the LMW fraction of EPS II was established to be crucial for formation of a biofilm with a highly ordered structure [15,16]. EPS II non-producing strains or those producing only the HMW fraction of this polysaccharide formed very low amounts of biofilm [15]. In the case of Rt2440 and Rt2441, the amount of LMW EPS was diminished, but the role of this fraction in biofilm formation remains to be elucidated. Beside rhizobial surface components, such as EPS and LPS, and quorum sensing systems, several other environmental factors affect biofilm formation, among them catabolite repression and nutrient limitation [63-65].

\section{Conclusions}

In the present study, we characterized ros $R$ mutants bearing a mutation in the gene encoding a transcriptional regulator with a $\mathrm{C}_{2} \mathrm{H}_{2}$ type zinc-finger motif. We demonstrated the importance of the intact ros $R$ gene both in the interaction with the host plant and in the bacterial adaptation to stress conditions. The pleiotropic effects of the rosR mutation confirmed the importance of this gene not only for exopolysaccharide production, but also for several other metabolic traits.

\section{Methods}

\section{Bacterial strains, plasmids, and growth conditions}

Bacterial strains, plasmids, and oligonucleotide primers used in this study are listed in Table 4. R. leguminosarum strains were grown in 79CA with $1 \%$ glycerol as a carbon source [66] and tryptone-yeast (TY) complex media, or M1 minimal medium [67] containing 1\% glycerol and Dilworth's vitamins [68] at $28^{\circ} \mathrm{C}$. E. coli strains were grown in Luria-Bertani (LB) medium at $37^{\circ} \mathrm{C}$ [67]. Where required, antibiotics for $E$. coli and $R$. leguminosarum were used at the following final concentrations: kanamycin, $40 \mu \mathrm{g} / \mathrm{ml}$; rifampicin $40 \mu \mathrm{g} / \mathrm{ml}$; ampicillin, $100 \mu \mathrm{g} / \mathrm{ml}$; tetracycline $10 \mu \mathrm{g} / \mathrm{ml}$; and nalidixic acid, $40 \mu \mathrm{g} / \mathrm{ml}$.

To assay the effect of clover root exudates on growth of the rosR mutants (Rt2441 and Rt2472) and the wild type, the strains were grown in $5 \mathrm{ml} \mathrm{M} 1$ medium supplemented with $5 \mu \mathrm{M}$ exudates, which was prepared as described previously [69]. After 24, 48, 72, and $96 \mathrm{~h}$, $100 \mu \mathrm{l}$ aliquots of each culture were removed and plated in dilutions on 79CA plates, incubated 4 days at $28^{\circ} \mathrm{C}$, and the colonies were counted.

\section{DNA methods: construction of Rt2441 rosR mutant and plasmids containing different fragments of the ros $R$ upstream region and rosR ORF}

Standard techniques were used for DNA isolation, restriction enzyme digestion, cloning, and Southern hybridization [67]. For PCR amplifications, Ready Taq PCR Reaction Mix (Sigma) or PfuI polymerase (Fermentas) was used. Sequencing was performed using the BigDye terminator cycle sequencing kit (Applied Biosystems) and the ABI Prism 310 sequencer.

To construct Rt2441 mutant with a genomic insertion of an additional copy of ros $R$ promoter region, $1.17-\mathrm{kb}$ fragment containing the entire promoter region and 5'-end of ros $R$ with $P s t \mathrm{I}$ internal restriction site was amplified using pB31 as a template and pEP1 and rosD primers. This amplicon was digested with EcoRI and PstI and cloned into respective sites of suicide integrative pK19mobGII vector, giving pM41. The obtained construct was verified by sequencing. The pM41 was introduced into $E$. coli S17-1 by transformation, and then transferred from $E$. coli S17-1 into R. leguminosarum bv. trifolii 24.2 via biparental conjugation. The transconjugants were selected on 79CA medium supplemented with nalidixic acid and kanamycin. The selected mutant was named Rt2441, and the insertion site was identified by PCR amplification (using primer sets: $\operatorname{ros} \mathrm{A} / \operatorname{ros} \mathrm{D}, \operatorname{ros} \mathrm{B} / \operatorname{ros} \mathrm{C}, \mathrm{pEP} 1 / \mathrm{pRR} 1, \mathrm{pEP} 5 / \mathrm{pRR} 1$, $\operatorname{ros} \mathrm{G} 1 / \mathrm{pRR} 1, \operatorname{ros} \mathrm{A} / \operatorname{ros} \mathrm{D} 4, \operatorname{ros} \mathrm{B} / \operatorname{ros} \mathrm{D} 5)$, and Southern hybridization with a probe amplified on pB31 as a template and $\mathrm{pEP} 1$ and rosD primers.

To construct a set of plasmids containing different fragments of the rosR upstream region, the following primer pairs were used: $\mathrm{pEP} 1 / \mathrm{pRR} 1, \mathrm{pEP} 1 / \mathrm{pEP} 8, \mathrm{pEP} 1 /$ pEP9, pEP6/pRR1 and pEP6/rosD. Genomic Rt24.2 DNA was used as a template, yielding $586 \mathrm{bp}, 372 \mathrm{bp}$, $219 \mathrm{bp}, 278 \mathrm{bp}$, and $820 \mathrm{bp}$ long amplicons. These PCR products were digested with: EcoRI and PstI enzymes (586 bp and $278 \mathrm{bp}$ fragments), EcoRI and $\mathrm{Xba \textrm {I }}$ (372 bp and 219 bp fragments) or EcoRI and BamHI (fragment $820 \mathrm{bp}$ ), and cloned into respective sites of pBBR1MCS-2 vector, giving plasmids pEX1, pEX60, pEX8, pEX9 and pBR28, respectively. The obtained constructs were introduced by transformation into $E$. coli S17-1, and then transferred into R. leguminosarum bv. trifolii 24.2 via biparental conjugation. The transconjugants were selected on 79CA medium supplemented with nalidixic acid and kanamycin.

\section{Phenotype analysis of rosR mutant using PM (Biolog) test} To compare a phenotype of the rosR mutant (Rt2472) with the wild type strain (Rt24.2), PM (Phenotype MicroArrays $^{\text {Tw' }}$, Biolog, USA) microplates PM1, PM2A, PM3B, PM4A and PM9 were used, according to manufacturer's instruction. Utilization of different carbon and energy sources by the strains was assayed using PM1 and PM2A microplates (190 compounds, including sugars and organic acids). PM3B plates were used for an examination of utilization of nitrogen sources (95 compounds), and PM4A plates of phosphorus and sulfur sources (94 compounds), accordingly. To test rhizobial growth under 
Table 4 Bacterial strains, plasmids, and primers used in this study.

\begin{tabular}{|c|c|c|}
\hline $\begin{array}{l}\text { Strain, plasmid or } \\
\text { oligonucleotide primers }\end{array}$ & Relevant characteristics & Reference \\
\hline $\begin{array}{l}\text { R. leguminosarum } \\
\text { bv. trifolii } 24.2\end{array}$ & Wild type, Rif', Nxr & [23] \\
\hline Rt2440 & Rt24.2 derivative carrying ros $R$ with one nucleotide deletion ( $\Delta C 177)$ & [23] \\
\hline Rt5819 & Rt24.2 derivative carrying the mini-Tn5 between $363-364$ bp position of pss $A$ & [30] \\
\hline Rt2472 & Rt24.2 derivative carrying the mini-Tn5 between $151-152$ bp position of ros $R$ & [30] \\
\hline Rt2441 & Rt24.2 with additional ros $R$ upstream region introduced by pM41 integration, $\mathrm{Km}^{r}, \mathrm{Nx}^{\mathrm{r}}$ & This work \\
\hline \multicolumn{3}{|l|}{ E. coli } \\
\hline $\mathrm{DH} 5 \alpha$ & supE44 $\triangle$ lacU169 ( $\phi 80$ lacZ $\triangle$ M15) hsdR17 recA1endA1gyrA96 thi-1 relA1 & [67] \\
\hline S17-1 & 294 derivative RP4-2Tc::Mu-Km::Tn7 chromosomally integrated & [79] \\
\hline \multicolumn{3}{|l|}{ Plasmids } \\
\hline pK19mobGll & mob, lacZ $\alpha$, gusA, $\mathrm{Km}^{\mathrm{r}}$ & [80] \\
\hline pBBR1MCS-2 & $m o b, l a c Z \alpha, \mathrm{Km}^{r}$ & [81] \\
\hline pB31 & pUC19 with 1174-bp BamHI fragment containing Rt24.2 rosR & [23] \\
\hline pM41 & pK19mobGIl with 586-bp EcoRl-Pstl fragment from pB31 containing the rosR upstream region & This work \\
\hline $\mathrm{pRC24}$ & pRK7813 with 1174-bp BamHI fragment containing rosR of Rt24.2 & [23] \\
\hline pBR24 & pBBR1MCS-5 with 1174-bp BamHI fragment containing rosR of Rt24.2 & [23] \\
\hline pEX1 & $\begin{array}{l}\text { pBBR1MCS-2 with 586-bp EcoRI-Pstl fragment containing the upstream region and the first } 60 \text { codons } \\
\text { for RosR }\end{array}$ & This work \\
\hline pEX8 & pBBR1MCS-2 with 372-bp EcoRI-Xbal fragment containing the $-403 \mathrm{bp}$ to $-32 \mathrm{bp}$ rosR upstream region & This work \\
\hline pEX9 & pBBR1MCS-2 with 219-bp EcoRI-Xbal fragment containing the $-403 \mathrm{bp}$ to $-185 \mathrm{bp}$ rosR upstream region & This work \\
\hline pEX60 & $\begin{array}{l}\text { pBBR1MCS- } 2 \text { with } 278-\mathrm{bp}(-96 \mathrm{bp} \text { to }+182 \mathrm{bp}) \text { EcoRI-Pstl fragment containing the first } 60 \text { codons for } \\
\text { RosR cloned downstream the vector promoter }\end{array}$ & This work \\
\hline pBR28 & $\begin{array}{l}\text { pBBR1MCS-2 with } 820-\mathrm{bp}(-96 \mathrm{bp} \text { to }+724 \mathrm{bp}) \text { EcoRl-BamHI fragment containing the full-length ros } R \\
\text { cloned downstream the vector promoter }\end{array}$ & This work \\
\hline $\mathrm{pHC60}$ & Vector with gfp and RK2 stabilization fragment, $T c^{r}$ & [39] \\
\hline Oligonucleotide primers & Sequence $\left(5^{\prime}-3^{\prime}\right)^{*}$ & \\
\hline pEP1 & ATGCAAGAATTCTGCACAGGAAGC & [23] \\
\hline pEP5 & CGGTCAGGAATTCTAAGAACAGGT & [23] \\
\hline pEP6 & TCGAAACAGGAATTCGATTCCTGC & [23] \\
\hline pRR1 & CGCATTCTAGACATGTGATCTGCT & [23] \\
\hline pEP8 & AACGGCTCTAGACTGACACGCCAAA & [23] \\
\hline pEP9 & TCATGCTCTAGACGATGGCCTCAGT & [23] \\
\hline rosA & GCGGATCCGCGACTTTACCAGATTTA & [23] \\
\hline $\operatorname{ros} \mathrm{B}$ & GTCACGCTCTTCGGAATTCAGGGGT & [23] \\
\hline $\operatorname{ros} C$ & AGGGATCCATTCTAAACCTGTCGGCA & [23] \\
\hline $\operatorname{ros} \mathrm{D}$ & TCGGATCCTGTCGGCAAAGCATAAGA & [23] \\
\hline $\operatorname{ros} \mathrm{G} 1$ & GACGATCGAATTCGGCCGTCTCTT & This work \\
\hline rosD4 & TTGCGGATCCGCAGATGCCGGT & This work \\
\hline $\operatorname{ros} \mathrm{D} 5$ & ACCACGCCTGGGATCCAGGAAAA & This work \\
\hline
\end{tabular}

* Sequences for EcoRl, BamHI and Xbal restriction sites are underlined.

various stress conditions, PM9 plates were used. Rt2472 and Rt24.2 strains growing $48 \mathrm{~h}$ at $28^{\circ} \mathrm{C}$ on $79 \mathrm{CA}$ agar medium were collected and washed twice with sterile water. Final suspensions $\left(\mathrm{OD}_{600}\right.$ of 0.1$)$ were prepared in sterile IF-0a fluid supplemented with Dilworth's vitamins, and $100 \mu \mathrm{l}$ aliquots were inoculated into microplate wells, and incubated at $28^{\circ} \mathrm{C}$ up to $72 \mathrm{~h}$. For PM3B and PM4A plates, $1 \%$ glycerol as a carbon source and $20 \mu \mathrm{M}$ $\mathrm{FeCl}_{3}$ were additionally added. Changes of color levels in the wells were monitored at the $\mathrm{OD}_{595}$ at regular time intervals using the Benchmark Plus ${ }^{\mathrm{Tw}}$ microplate reader (Bio-Rad Laboratories, USA). The experiment was repeated twice.

\section{Assays for sensitivity to antibiotics, detergents, and osmotic stress}

The sensitivity of $R$. leguminosarum bv. trifolii strains to sodium deoxycholate (DOC), sodium dodecyl sulfate (SDS), and ethanol was studied, and minimal inhibitory concentration of particular agents was determined. 
Bacteria were collected from TY agar medium into sterile water to an $\mathrm{OD}_{600}$ of 0.3 and $10 \mu \mathrm{l}$ of each suspension was plated on TY containing a defined concentration of DOC $(0.005-1 \% \mathrm{w} / \mathrm{v})$, SDS $(0.005-1 \%$ $\mathrm{w} / \mathrm{v})$ or ethanol $(0.25-6 \% \mathrm{v} / \mathrm{v})$. After 3 days, the growth of strains on individual media was determined. Three independent experiments were done for each strain.

To assess the effect of osmolarity on growth of the $R$. leguminosarum bv. trifolii Rt24.2 and the rosR mutants, the strains were grown in TY medium supplemented with a defined concentration of $\mathrm{NaCl}(0-510 \mathrm{mM})$. Cultures were incubated at $28^{\circ} \mathrm{C}$ for $48 \mathrm{~h}$, and then the $\mathrm{OD}_{600}$ was measured. Tolerance to hypo-osmotic stress was determined using low-osmolarity glutamate-yeast extractmannitol (GYM) medium [35]. Antibiotic sensitivity assays were performed using commercially available filter disks with the appropriate antibiotic: ampicillin $(10 \mu \mathrm{g})$, erythromycin $(15 \mu \mathrm{g})$, chloramphenicol $(30 \mu \mathrm{g})$, gentamicin $(10$ $\mu \mathrm{g})$, bacitracin $(10 \mu \mathrm{g})$, augmentin $(30 \mu \mathrm{g})$, streptomycin $(10 \mu \mathrm{g})$, polymyxin B $(10 \mu \mathrm{g})$, carbenicillin $(20 \mu \mathrm{g})$, penicillin G (10 U), and tetracycline $(30 \mu \mathrm{g})$ (Mast Diagnostics, Merseyside, UK). Filter disks were placed on the surface of 79CA medium, where $100 \mu \mathrm{l}$ of $R$. leguminosarum cultures were previously spread. The diameter of the growth inhibition zone was measured after 3 days of incubation.

\section{Isolation and analysis of extracellular and membrane proteins}

For analysis of extracellular and membrane proteins, the Rt2472 and Rt24.2 strains were grown at $28^{\circ} \mathrm{C}$ for 2 days to an $\mathrm{OD}_{600}$ of 0.6 in $200 \mathrm{ml}$ TY medium. To study the influence of clover root exudates on membrane protein profiles, these strains were grown at $28^{\circ}$ $\mathrm{C}$ for 3 days in $400 \mathrm{ml} \mathrm{M} 1$ medium supplemented with Dilworth's vitamins and with or without $5 \mu \mathrm{M}$ exudates. Cells were removed by twice centrifugation at $5,000 \times \mathrm{g}$ for $20 \mathrm{~min}$ at $4{ }^{\circ} \mathrm{C}$, and supernatants were used for purification of extracellular proteins. The proteins were concentrated by precipitation with $10 \%$ trichloroacetic acid according to the procedure by Russo et al. [14]. Membrane proteins from cell pellets were isolated according to the method described by Kucharczyk et al. [70]. The cells were washed in 200 $\mathrm{ml} 50 \mathrm{mM}$ Tris- $\mathrm{HCl}(\mathrm{pH} 7.4)$, and centrifuged at 5,000 $\times g$ for $20 \mathrm{~min}$ at $4^{\circ} \mathrm{C}$. Cell pellet was resuspended in $1.6 \mathrm{ml} 200 \mathrm{mM}$ Tris- $\mathrm{HCl}(\mathrm{pH} 8.0)$, and then $1.6 \mathrm{ml} 1$ $\mathrm{M}$ sucrose in $200 \mathrm{mM}$ Tris- $\mathrm{HCl}(\mathrm{pH} 8.0), 16 \mu l$ lysozyme $(12 \mathrm{mg} / \mathrm{ml}$ in $100 \mathrm{mM}$ EDTA, $\mathrm{pH} 8.0)$ and 3.2 $\mathrm{ml}$ ice cold water were added. Next, $25.6 \mu \mathrm{l}$ saturated ethanol-phenylmethylsulfonylfluoride (PMSF) solution and $12.8 \mu \mathrm{l} 1 \mathrm{M}$ dithiotreitol (DTT) were added, and probes were left on ice for $10 \mathrm{~min}$. The cells were disrupted by sonication $(8 \times 10 \mathrm{~s}, 30 \mathrm{~s}$ breaks on ice, 50\%) using the Misonix XL 2929 Sonicator Ultrasonic
Processor with Cabinet (Misonix, Farmingdale, NY, USA). Unbroken cells were removed by centrifugation at $5,000 \times g$ for $20 \mathrm{~min}$. Supernatant was collected and transferred on the top of two-step sucrose gradient, containing $1 \mathrm{ml} 55 \%(\mathrm{w} / \mathrm{v})$ sucrose in $3 \mathrm{mM}$ EDTA $(\mathrm{pH}$ 8.0) on the bottom of an ultracentrifuge tube and $5 \mathrm{ml} 17 \%(\mathrm{w} / \mathrm{v})$ sucrose on the top. The supernatant was subsequently centrifuged at $30,000 \times g$ for $90 \mathrm{~min}$ to separate the membrane fraction from the cytosolic fraction. To membrane fractions equal volume of 3 mM EDTA ( $\mathrm{pH} 8.0$ ), and then 50\% trichloroacetic acid (TCA) to the final concentration of $8 \%$ was added, and left overnight at $4^{\circ} \mathrm{C}$. For protein precipitation, probes were centrifuged $60 \mathrm{~min}$ at $10,000 \times g$ at $8^{\circ} \mathrm{C}$, washed twice with acetone, each time spinning $15 \mathrm{~min}$ at $10,000 \times g$, air dried and final pellet was resuspended in $200 \mu \mathrm{l}$ loading buffer. The protein concentration in the final preparations was determined using the Bradford kit (Bio-Rad). Secreted and membrane proteins of the Rt24.2 and the Rt2472 were separated by SDSPAGE with $12 \%$ acrylamide and visualized by staining with Coomassie brilliant blue G-250.

\section{Protein sequencing}

Membrane and extracellular protein fractions of Rt24.2 and Rt2472 separated by SDS-PAGE electrophoresis were transferred onto polyvinylidene difluoride (PVDF) membrane (Sequi-Blot; Bio-Rad) using the buffer containing 2.2\% 3-(cyclohexylamino)-1-propanesulfonic acid (CAPS) (w/v), 10\% methanol (v/v) (pH 11). Proteins were visualized by staining with Coomassie brilliant blue R-250, and interesting bands were excised from the membrane for the analysis. Protein sequencing was performed in BioCentrum sp. z o.o. Service lab in Cracow, Poland. Amino acids abstracted sequentially from the N-terminus in the form of phenylthiohydantoin derivatives (PTH) were analyzed using the automatic sequencer Procise 491 (Applied Biosystems, Foster City, CA, USA) and following standard manufacturer's protocols.

\section{Immunoblotting}

Proteins separated by SDS-PAGE were transferred onto polyvinylidene difluoride (PVDF) membrane (Immobilon P; Millipore). Following transfer, the membrane was blocked with $3 \%(\mathrm{w} / \mathrm{v})$ low fat milk in TBS buffer for $1 \mathrm{~h}$, and incubated $1 \mathrm{~h}$ with rabbit polyclonal antibodies against PssB cytoplasmic protein [39] or PssN outer membrane protein [40] diluted 1:20000 and 1:40000, respectively. The membrane was washed 3 times for 10 min with TBS, and incubated for $2 \mathrm{~h}$ with 1:30000 dilution of alkaline phosphate-conjugated goat anti-rabbit IgG (Sigma). The membrane was visualized with alkaline phosphatase substrates (nitro tetrazolium blue and 
5-bromo-4-chloro-3-indolylphosphate, NBT/BCIP, Roche) in a color development buffer.

\section{EPS and LPS isolation}

For large-scale EPS isolation, 500-ml cultures of rhizobial strains were grown in 79CA medium with $1 \%$ glycerol for 5 days at $28^{\circ} \mathrm{C}$ in a rotary shaker. EPS was precipitated from supernatants with three volumes of cold ethanol. After centrifugation, the acidic EPS was dissolved and further fractionated by $2 \%$ hexadecyltrimethylammonium bromide (cetrimide) precipitation. The precipitate was dissolved in $1 \mathrm{M} \mathrm{NaCl}$ and reprecipitated with 3 volumes of ethanol. After the solubilization in water, the samples were dialyzed $(12 \mathrm{kDa}$ MWCO) against water, passed through the column with Dowex $50 \mathrm{~W} \times 8\left[\mathrm{H}^{+}\right]$to remove sodium ions and lyophilized. EPS samples were size-fractionated by column chromatography. Bio-Gel A-5m (Bio-Rad, Hercules, CA, USA) column $(1.6 \times 60 \mathrm{~cm})$ equilibrated with sodium phosphate buffer $(50 \mathrm{mM}, \mathrm{pH} 7.0)$ containing $100 \mathrm{mM}$ sodium chloride as described in [71] was loaded with EPS samples. Fractions were collected and assayed for carbohydrates by the indole - sulphuric acid method. Total sugar content was calculated as glucose equivalents.

Prior to LPS isolation, bacterial cells were washed three times with $0.9 \% \mathrm{NaCl}$ solution to remove extracellular polysaccharides. LPS was extracted using the hot phenol procedure and the aqueous phase was dialyzed against water. The water phase LPS was brought to 50 $\mathrm{mM}$ Tris- $\mathrm{HCl}$, supplemented with $1 \mathrm{mM} \mathrm{MgCl}_{2}(\mathrm{pH}$ 7.0), and treated with RNase A (500 units) for $6 \mathrm{~h}$ at $37^{\circ}$ $\mathrm{C}$, followed by proteinase $\mathrm{K}(0.1 \mathrm{mg} / \mathrm{ml})$ digestion for 60 min at $60^{\circ} \mathrm{C}$. The LPS preparations were pelleted by centrifugation at $105,000 \times g$ for $4 \mathrm{~h}$. To remove any attached glucans, LPS was purified by an extraction into $80 \%$ aqueous phenol and precipitation with 10 volumes of cold 95\% ethanol. Finally, the precipitate was dissolved in carbonate buffer and submitted to polymyxin agarose affinity column chromatography as described by Kannenberg and Carlson [72]. The LPS preparations eluted from polymyxin column by carbonate buffer containing $1 \%$ deoxycholate were used for GC-MS analysis, and were separated by $12.5 \%$ Tricine SDS-PAGE and visualized by silver staining [73].

\section{EPS and LPS analysis}

The sugar composition of the degraded polysaccharides liberated from LPSs of the wild type and Rt 2440 by mild acid hydrolysis $\left(1 \%\right.$ acetic acid, $\left.100^{\circ} \mathrm{C}, 90 \mathrm{~min}\right)$ was determined by GC-MS analysis of their alditol acetates. For this, water soluble degraded polysaccharide obtained after lipid A centrifugation was subjected to reduction $\left(\mathrm{NaBH}_{4}, 25^{\circ} \mathrm{C}, 90 \mathrm{~min}\right)$. For the determination of acid sugars, the samples were subjected to methanolysis at $85^{\circ} \mathrm{C}$ for $16 \mathrm{~h}$ in $1 \mathrm{M}$ methanolic $\mathrm{HCl}$, carboxyl reduction with $\mathrm{NaBD}_{4}$, hydrolysis with $2 \mathrm{M}$ trifluoroacetic acid (TFA) for $4 \mathrm{~h}$ at $100^{\circ} \mathrm{C}$, reduction with $\mathrm{NaBD}_{4}$, and acetylation. For the neutral and amino sugar analysis, the samples were hydrolyzed with $2 \mathrm{M}$ TFA, N-acetylated prior to reduction with $\mathrm{NaBD}_{4}$, and acetylated.

The glycosyl composition analysis of EPS samples was performed after methanolysis, followed by trimethylsilylation as described in Vanderlinde et al. [74]. Part of the methanolysates was subjected to carboxyl reduction $\left(\mathrm{NaBD}_{4}\right)$, hydrolysis in $2 \mathrm{~N}$ TFA, reduction and acetylation, as in the procedure described above for the acidic sugar determination in LPS. Monosaccharides in the form of alditol acetates and methyl glycosides of trimethylsilyl ethers were analysed by GC-MS on the Hewlett-Packard (5890) gas chromatograph interfaced to the 5971 mass selective detector using the $30 \mathrm{~m} \mathrm{HP}-5 \mathrm{MS}$ capillary column (temperature program $150^{\circ} \mathrm{C}$ for $5 \mathrm{~min}$, raised to $310^{\circ} \mathrm{C}$ at $5^{\circ} \mathrm{C} / \mathrm{min}$ ).

NMR spectroscopy $-{ }^{1} \mathrm{H}$ experiments were recorded with the Varian Unity plus 500 instrument in $\mathrm{D}_{2} \mathrm{O}$ solutions at $70^{\circ} \mathrm{C}$ with acetone as an internal standard (d $2.225 \mathrm{ppm}$ ) using standard Varian software.

\section{Motility assay}

$R$. leguminosarum motility assay was conducted in $0.3 \%$ M1 agar medium. $5 \mu \mathrm{l}$ culture grown in liquid TY medium at $28^{\circ} \mathrm{C}$ for $24 \mathrm{~h}$ to an $\mathrm{OD}_{600}$ of 0.4 was stabbed into plates with M1 medium. To eliminate the flocculation of the rosR mutants, cell clumps were wiped and broken up on the inner surface of a glass tube using a sterile wooden stick. Then, the tube was left standing for $15 \mathrm{~min}$ so that the remaining clumps sunk to the bottom. The suspended cells from the top were taken carefully and, if needed, diluted down into TY to get the desired cell density $\left(\mathrm{OD}_{600}\right.$ of 0.4$)$. The plates were incubated at $28^{\circ} \mathrm{C}$ for 3 days, and bacterial growth from the point of inoculation was measured. Motility assay was done twice in triplicate.

\section{Biofilm formation assay - microtiter plate method}

The biofilm formation assay was done according to method described by Rinaudi and Gonzalez [15]. Briefly, $R$. leguminosarum strains were grown in M1 medium supplemented with Dilworth's vitamins at $28^{\circ} \mathrm{C}$ for $48 \mathrm{~h}$. The cultures were diluted to an $\mathrm{OD}_{600}$ of 0.4 , inoculated into the polystyrene microplate wells in $100 \mu \mathrm{l}$ aliquots, and incubated with agitation $(100 \mathrm{rpm})$ at $28^{\circ} \mathrm{C}$ for $48 \mathrm{~h}$. After this time, bacterial growth was assessed by measuring the $\mathrm{OD}_{600}$. The contents of wells were removed and each well was washed three times with $150 \mu \mathrm{l}$ of $0.85 \% \mathrm{NaCl}$, stained for $15 \mathrm{~min}$ with $150 \mu \mathrm{l}$ of $0.1 \%$ crystal violet, and then rinsed three times with water. 
Biofilm formation was quantified by the addition of $150 \mu \mathrm{l}$ of $95 \%$ ethanol and measurement of the absorbance at $560 \mathrm{~nm}$ in a microplate reader. The experiment was performed in triplicate, repeated three times, and averaged.

\section{Confocal laser scanning microscopy}

To visualize different stages of $R$. leguminosarum biofilm formation in a 4-day time-course experiment in polystyrene microplate wells, the inverted microscope Axiovert $200 \mathrm{M}$ equipped with LSM 5 Pascal head (with magnification 200x) was used. To obtain images of biofilm formation, bacterial cultures were stained with either Calcofluor (Sigma) or Bacterial Viability kit LIVE/ DEAD BacLight ${ }^{\text {tw }}$ (Invitrogen). Calcofluor was used for general visualization of the biofilm surface and structure, and two components of Bacterial Viability kit for the determination of a ratio of live (stained with Syto-9) to dead (stained with propidium iodide) cells in biofilm [75]. Bacterial cultures growing in TY medium for $48 \mathrm{~h}$ to an $\mathrm{OD}_{600}$ of 0.6 were diluted 1000 -fold in M1 minimal medium supplemented with Dilworth's vitamins, and $100 \mu \mathrm{l}$ of diluted cultures were added to each well and grown under static conditions at $28^{\circ} \mathrm{C}$ for up to 4 days. After 2 and 4 days, the contents of the wells were removed and each well was washed two times with 150 $\mu \mathrm{l}$ of sterile physiological saline solution, and then stained for $30 \mathrm{~min}$ with $100 \mu \mathrm{l}$ of $25 \mu \mathrm{g} / \mathrm{ml}$ Calcofluor or $100 \mu \mathrm{l}$ of $0.85 \% \mathrm{NaCl}$ containing $5 \mu \mathrm{M}$ Syto- 9 and 30 $\mu \mathrm{M}$ propidium iodide. Next, dye solutions were removed and the wells were washed three times with $150 \mu \mathrm{l}$ of $0.85 \% \mathrm{NaCl}$, covered by $30 \mu \mathrm{l}$ of fresh portion of physiological saline solution, and observed in a microscope. This experiment was repeated two times. To analyze different parameters of biofilm, 36 images from 3 wells of individual strain were collected. The ratio of live to dead cells was calculated using the Image J 1.43e software (Wayne Rasband, NIH, USA). Images of biofilms stained with Syto-9 were analyzed to calculate several morphological parameters. The percentage of area covered by biofilm, a fractal dimension, and the length of coastline were calculated using ImageJ 1.43e software according to $[76,77]$. Three-dimensional images were reconstructed using the Laser Scanning Confocal Microscope LSC 5 PASCAL (Carl Zeiss, Germany) with 200x magnification.

\section{Plant tests}

Red clover (Trifolium pratense cv. Diana) seeds were surface sterilized, germinated and grown on Fåhraeus medium [66] slants. 5-day-old seedlings were inoculated with bacterial suspensions at an $\mathrm{OD}_{600}$ of $0.2(200 \mu \mathrm{l} /$ plant), and grown under natural light supplemented with artificial light $\left(14 \mathrm{~h}\right.$ day at $24^{\circ} \mathrm{C}$ and $10 \mathrm{~h}$ night at $18^{\circ} \mathrm{C}$ ) in a greenhouse. The clover plants were inspected for root nodule formation and harvested after 4 weeks. Wet and dry masses of clover shoots were estimated.

\section{Plant competition assay}

For the competition assay, the Rt2472 and Rt2441 mutants, and the wild type Rt24.2 were collected from $\mathrm{TY}$ agar medium into sterile water to an $\mathrm{OD}_{600}$ of 0.1 . The mutants and wild type suspensions were mixed in $1: 1,10: 1,100: 1$, and 1000:1 ratios, and $200 \mu \mathrm{l}$ of each mixture were added per plant. Twenty seedlings were used for each treatment. 28 days after infection, nodules were surface sterilized, crushed in $20 \mu \mathrm{l}$ of saline solution, and $10 \mu \mathrm{l}$ portions were plated on 79CA agar plates supplemented with nalidixic acid or kanamycin, and incubated at $28^{\circ} \mathrm{C}$ for 3 days. Ninety nodules per each mixture were examined. Bacteria growing exclusively on the medium supplemented with nalidixic acid corresponded to the wild type strain, and those growing on the medium supplemented with kanamycin corresponded to the rosR mutants. The competitive ability of rhizobia was expressed as the percentage of the particular strain in the analyzed nodules.

\section{Assays for root attachment and growth on the root surface}

Root attachment of the Rt2472 and the Rt24.2 carrying pHC60 with a constitutively expressed $g f p$ [42] was assayed according to the method described by Williams et al. [18]. The strains were grown in $79 \mathrm{CA}$ to an $\mathrm{OD}_{600}$ of $\sim 0.6$, washed twice in sterile water, and resuspended in $25 \mathrm{mM}$ phosphate buffer $\left(\mathrm{pH}\right.$ 6.8) to a final $\mathrm{OD}_{600}$ of 0.06. $200 \mu \mathrm{l}$ of a bacterial suspension was placed onto a slide with modified Fåhraeus medium containing a sterile germinated clover seedling with root $\sim 2 \mathrm{~cm}$ long. The slides were incubated for $90 \mathrm{~min}$ at room temperature, and root attachment of tested strains was observed under confocal laser scanning microscopy. To study plant root invasion by the Rt2472 and the Rt24.2, clover seedlings $\sim 2 \mathrm{~cm}$ long were placed on the top of microscope slides, which were previously covered with $2 \mathrm{ml}$ Fåhraeus agar, and inoculated with $100 \mu \mathrm{l}$ of bacterial suspension in sterile water of $\mathrm{OD}_{600}$ of 0.08 [42]. The slides with seedlings were placed in $50-\mathrm{ml}$ culture tubes containing $5 \mathrm{ml}$ of liquid Fåhraeus medium and covered loosely by sterile Whatman paper. To determine the efficiency of invasion, 25 plants inoculated with the particular strain were examined after $3,4,6,8$, and 10 days.

To determine quantitatively adhesion efficiency and the growth rate on clover roots by the Rt2472 and Rt24.2, the methods described by Fujishige et al. 2006 [78] were applied. For adhesion assay, three-day-old seedlings were inoculated by dipping their roots into bacterial suspensions of $\mathrm{OD}_{600}$ of 0.08 for $30 \mathrm{~min}$ or 
placed on Fåhraeus agar medium plates, inoculated by bacterial suspensions of $\mathrm{OD}_{600}$ of $0.08(100 \mu \mathrm{l}$ per seedling), and incubated for two days. The seedlings were placed on sterile Whatman paper to remove the excess of liquid, and subsequently were grown on Whatman paper wetted with liquid Fåhraeus medium for $48 \mathrm{~h}$. Next, roots were washed overnight with sterile water containing $0.05 \%$ Tween- 20 on a rocking platform shaker to remove loosely associated cells. After removing the excess of liquid, the roots were weighed. To determine the number of attached bacteria, the root of each seedling was homogenized in $300 \mu \mathrm{l}$ of water and root homogenate was plated in dilutions on 79CA plates for colony counting.

\section{Additional material}

\section{Additional file 1: Figure $\mathrm{S} 1$ - Western blotting analysis of} membrane and extracellular protein fractions of the $R$. leguminosarum wild type and the ros $R$ mutant (Rt2472) with polyclonal antisera against PssB (A) and PssN (B). The migration positions of molecular mass markers are shown. Lines 1-6: extracellular protein fractions isolated from $10 \mathrm{ml}$ of: Rt24.2 TY culture supernatant (1), Rt2472 TY culture (2), Rt24.2 M1 culture (3), Rt24.2 M1 culture with $5 \mu \mathrm{M}$ exudates (4), Rt2472 M1 culture (5), Rt2472 M1 culture with $5 \mu \mathrm{M}$ exudates (6). Lines 7-12: $6 \mu \mathrm{g}$ of membrane protein fractions isolated from: Rt24.2 cells grown in TY (7), Rt2472 cells grown in TY (8), Rt24.2 cells grown in $\mathrm{M} 1$ (9), Rt 24.2 cells grown in $\mathrm{M} 1$ with $5 \mu \mathrm{M}$ exudates (10), Rt2472 cells grown in M1 (11), Rt2472 cells grown in M1 with $5 \mu M$ exudates (12), Lines: 13 and 14 - cytoplasmic protein fractions of Rt24.2 and Rt2472, respectively, grown in M1 medium.

\section{Acknowledgements}

This research has been supported by the grant from the Ministry of Science and Higher Education no. N N303 092234. The authors would like to thank Prof. Teresa Urbanik-Sypniewska for help in the preparation and analyses of EPS and LPS. We thank Mrs Maria Małek for technical assistance.

\section{Author details}

'Department of Genetics and Microbiology, University of M. CurieSkłodowska, Akademicka 19, 20-033 Lublin, Poland. ${ }^{2}$ Department of Comparative Anatomy and Anthropology, University of M. Curie-Skłodowska, Akademicka 19, 20-033 Lublin, Poland.

\section{Authors' contributions}

MJ performed genetic analyses of the ros $R$ mutants, carried out experiments concerning their phenotype characterization and plant experiments, and drafted the manuscript. JK conducted EPS and LPS analyses, TP performed microscope images and parameter analyses of biofilm. AS discussed the results and elaborated the final version of manuscript. All authors read and approved the final version of the manuscript.

Received: 21 April 2010 Accepted: 11 November 2010 Published: 11 November 2010

\section{References}

1. Fraysse N, Couderc F, Poinsot V: Surface polysaccharide involvement in establishing the rhizobium - legume symbiosis. Eur J Biochem 2003, 270:1365-1380.

2. Gage DJ: Infection and invasion of roots by symbiotic, nitrogen-fixing rhizobia during nodulation of temperate legumes. Microbiol Mol Biol Rev 2004, 68:280-300.
3. Mathis R, Van Gijsegem F, De Rycke R, D'Haeze W, Van Maelsaeke E, Anthonio E, Van Montagu M, Holsters M, Vereecke D: Lipopolysaccharides as a communication signal for progression of legume endosymbiosis. Proc Natl Acad Sci USA 2005, 102:2655-2660.

4. Jones KM, Kobayashi H, Davies BW, Taga ME, Walker GC: How rhizobial symbionts invade plants: the Sinorhizobium - Medicago model. Nat Rev Microbiol 2007, 5:619-633.

5. Becker A, Pühler A: Production of exopolysaccharides. In Rhizobiaceae. Molecular Biology of Plant-Associated Bacteria. Edited by: Spaink HP, Kondorosi A, Hooykaas PJJ. Kluwer Dordrecht: Academic Press; 1998:97-118.

6. Skorupska A, Janczarek M, Marczak M, Mazur A, Król J: Rhizobial exopolysaccharides: genetic control and symbiotic functions. Microb Cell Fact 2006, 5:7.

7. Hollingsworth RI, Dazzo FB, Hallenga K, Musselman B: The complete structure of the trifoliin A lectin-binding capsular polysaccharide of Rhizobium trifolii 843. Carbohydr Res 1988, 172:97-112.

8. O'Neill MA, Darvill AG, Albersheim P: The degree of esterification and points of substitution by $\mathrm{O}$-acetyl and $\mathrm{O}$-(3-hydroxybutanoyl) groups in the acidic extracellular polysaccharides secreted by Rhizobium leguminosarum biovars viciae, trifolii, and phaseoli are not related to host range. J Biol Chem 1991, 266:9549-9555.

9. Borthakur D, Barker CE, Lamb JW, Daniels MJ, Downie JA, Johnston AWB: A mutation that blocks exopolysaccharide synthesis prevents nodulation of peas by Rhizobium leguminosarum but not of beans by $R$. phaseolii and is corrected by cloned DNA from Rhizobium or the phytopathogen Xanthomonas. Mol Gen Genet 1986, 203:320-323.

10. Rolfe BG, Carlson RW, Ridge RW, Dazzo RW, Mateos FB, Pankhurst CE: Defective infection and nodulation of clovers by exopolysaccharide mutants of Rhizobium leguminosarum bv. trifolii. Aust J Plant Physiol 1996, 23:285-303.

11. van Workum WAT, van Slageren S, van Brussel AAN, Kijne JW: Role of exopolysaccharides of Rhizobium leguminosarum bv. viciae as host plantspecific molecules required for infection thread formation during nodulation of Vicia sativa. Mol Plant Microbe Interact 1998, 11:1233-1241.

12. Young JPW, Crossman LC, Johnston AWB, Thomson NR, Ghazoui ZF, Hull KH, Wexler M, Curson ARJ, Todd JD, Poole PS, Mauchline TH, East AK, Quail MA, Churcher C, Arrowsmith C, Cherevach I, Chillingworth T, Clarke K, Cronin A, Davis P, Fraser A, Hance Z, Hauser $H$, Jagels K, Moule $S$, Mungall K, Norbertczak H, Rabbinowitsch E, Sanders M, Simmonds M, Whitehead S, Parkhill J: The genome of Rhizobium leguminosarum has recognizable core and accessory components. Genome Biol 2006, 7:R34.

13. Król JE, Mazur A, Marczak M, Skorupska A: Syntenic arrangements of the surface polysaccharide biosynthesis genes in Rhizobium leguminosarum. Genomics 2007, 89:237-247.

14. Russo DM, Williams A, Edwards A, Posadas DM, Finnie C, Dankert M, Downie JA, Zorreguieta A: Proteins exported via the PrsD-PrsE type I secretion system and the acidic exopolysaccharide are involved in biofilm formation by Rhizobium leguminosarum.. J Bacteriol 2006, 188:4474-4486.

15. Rinaudi LV, González JE: The low-molecular-weight fraction of the exopolysaccharide II from Sinorhizobium meliloti is a crucial determinant of biofilm formation. J Bacteriol 2009, 191:7216-7224.

16. Rinaudi LV, Sorroche F, Zorreguieta A, Giordano W: Analysis of the mucR gene regulating biosynthesis of exopolysaccharides: implications for biofilm formation in Sinorhizobium meliloti Rm1021. FEMS Microbiol Lett 2010, 302:15-21.

17. Downie JA: The roles of extracellular proteins, polysaccharides and signals in the interactions of rhizobia with legume roots. FEMS Microbiol Rev 2010, 34:150-170.

18. Williams A, Wilkinson A, Krehenbrink M, Russo D, Zorreguieta A, Downie JA: Glucomannan-mediated attachment of Rhizobium leguminosarum to pea root hairs is required for competitive nodule infection. J Bacteriol 2008, 190:4706-4715.

19. Finnie C, Hartley NM, Findlay KC, Downie JA: The Rhizobium leguminosarum prs $D E$ genes are required for secretion of several proteins, some of which influence nodulation, symbiotic nitrogen fixation and exopolysaccharide modification. Mol Microbiol 1997, 25:135-146.

20. Zorreguieta A, Finnie C, Downie JA: Extracellular glycanases of Rhizobium leguminosarum are activated on the cell surface by an exopolysaccharide-related component. J Bacteriol 2000, 182:1304-1312. 
21. Ausmees N, Jacobsson K, Lindberg M: A unipolarly located, cell-surfaceassociated agglutinin, RapA, belongs to a family of Rhizobium-adhering proteins (Rap) in Rhizobium leguminosarum bv. trifolii. Microbiology 2001, 147:549-559.

22. Krehenbrink M, Downie JA: Identification of protein secretion systems and novel secreted proteins in Rhizobium leguminosarum bv. viciae. BMC Genomics 2008, 9:55.

23. Janczarek M, Skorupska A: The Rhizobium leguminosarum bv. trifolii RosR transcriptional regulator involved in exopolysaccharide production. Mol Plant Microbe Interact 2007, 20:867-881.

24. Bittinger MA, Milner JL, Saville BJ, Handelsman J: $\operatorname{ros} R$, a determinant of nodulation competitiveness in Rhizobium etli. Mol Plant Microbe Interact 1997, 10:180-186.

25. Keller M, Roxlau A, Weng WM, Schmidt M, Quandt J, Niehaus K, Jording D, Arnold W, Pühler A: Molecular analysis of the Rhizobium meliloti mucR gene regulating the biosynthesis of the exopolysaccharides succinoglycan and galactoglucan. Mol Plant Microbe Interact 1995, 8:267-277.

26. Chou AY, Archdeacon J, Kado Cl: Agrobacterium transcriptional regulator Ros is a prokaryotic zinc finger protein that regulates the plant oncogene ipt. Proc Natl Acad Sci USA 1998, 95:5293-5298.

27. Hussain $\mathrm{H}$, Johnston AW: Iron-dependent transcription of the regulatory gene ros of Agrobacterium radiobacter. Mol Plant Microbe Interact 1997, 10:1087-1093.

28. Bittinger MA, Handelsman J: Identification of genes in the RosR regulon of Rhizobium etli. J Bacteriol 2000, 182:1706-1713.

29. Janczarek M, Skorupska A: Rhizobium leguminosarum bv. trifolii rosR gene expression is regulated by catabolic repression. FEMS Microbiol Lett 2009, 291:112-119.

30. Janczarek M, Jaroszuk-Ściseł J, Skorupska A: Multiple copies of rosR and pssA genes enhance exopolysaccharide production, symbiotic competitiveness and clover nodulation in Rhizobium leguminosarum bv. trifolii. Antonie Van Leeuwenhoek 2009, 96:471-486.

31. Forsberg LS, Bhat UR, Carlson RW: Structural characterization of the Oantigenic polysaccharide of the lipopolysaccharide from Rhizobium etli strain CE3. A unique O-acetylated glycan of discrete size, containing 3O-methyl-6-deoxy-L-talose and 2,3,4-tri-O-methyl-L-fucose. J Biol Chem 2000, 275:18851-18863.

32. Noel KD, Forsberg LS, Carlson RW: Varying the abundance of $O$ antigen in Rhizobium etli and its effect on symbiosis with Phaseolus vulgaris. $J$ Bacteriol 2000, 182.5317-5324.

33. Nikaido H: Molecular basis of bacterial outer membrane permeability revisited. Microbiol Mol Biol Rev 2003, 67:593-656.

34. Breedveld MW, Miller KJ: Synthesis of glycerophosphorylated cyclic $(1,2)$ ß-glucans in Rhizobium meliloti strain 1021 after osmotic shock. Microbiology 1995, 141:583-588

35. Vanderlinde EM, Muszyński A, Harrison JJ, Koval SF, Foreman DL, Ceri H, Kannenberg EL, Carlson RW, Yost CK: Rhizobium leguminosarum biovar viciae 3841, deficient in 27-hydroxyoctacosanoate-modified lipopolysaccharide, is impaired in desiccation tolerance, biofilm formation and motility. Microbiology 2009, 155:3055-3069.

36. De Maagd RA, Mulders IHM, Canter Cremers HCJ, Lugtenberg BJJ: Cloning, nucleotide sequencing and expression in Escherichia coli of a Rhizobium leguminosarum gene encoding a symbiotically repressed outer membrane protein. J Bacteriol 1992, 174:214-221.

37. Roest HP, Mulders IHM, Wijffelman CA, Lugtenberg BJJ: Isolation of ropB, a gene encoding a 22-kDa Rhizobium leguminosarum outer membrane protein. Mol Plant Microbe Interact 1995, 8:576-583.

38. Roest HP, Bloemendaal CP, Wijffelman CA, Lugtenberg BJJ: Isolation and characterization of ropA homologous genes from Rhizobium leguminosarum biovars viciae and trifolii. J Bacteriol 1995, 177:4985-4991.

39. Janczarek M, Skorupska A: The Rhizobium leguminosarum bv. trifolii pssB gene product is an inositol monophosphatase that influences exopolysaccharide synthesis. Arch Microbiol 2001, 175:143-151.

40. Marczak M, Mazur A, Król JE, Gruszecki WI, Skorupska A: Lipoprotein PssN of Rhizobium leguminosarum bv. trifolii: subcellular localization and possible involvement in exopolysaccharide export. J Bacteriol 2006, 188:6943-52.

41. Bochner BR, Gadzinski P, Panomitros E: Phenotype microarrays for highthroughput phenotypic testing and assay of gene function. Genome Res 2001, 11:1246-1255.
42. Cheng HP, Walker GC: Succinoglycan is required for initiation and elongation of infection threads during nodulation of alfalfa by Rhizobium meliloti. J Bacteriol 1998, 180:5183-5191.

43. Brightwell G, Hussain H, Tiburtius A, Yeoman KH, Johnston AW: Pleiotropic effects of regulatory ros mutants of Agrobacterium radiobacter and their interaction with Fe and glucose. Mol Plant Microbe Interact 1995, 8:747-754

44. van Workum WAT, van Slageren S, van Brussel AAN, Kijne JW: Role of exopolysaccharides of Rhizobium leguminosarum bv. viciae as host plantspecific molecules required for infection thread formation during nodulation of Vicia sativa.. Mol Pant Microbe Interact 1998, 11:1233-1241.

45. Yao SY, Luo L, Har K, Becker A, Rüberg S, Yu GQ, Zhu JB, Cheng HP: Sinorhizobium meliloti ExoR and ExoS proteins regulate both succinoglycan and flagellum production. J Bacteriol 2004, 186:6042-6049.

46. Foreman DL, Vanderlinde EM, Bay DC, Yost CK: Characterization of a gene family of outer membrane proteins (ropB) in Rhizobium leguminosarum bv. viciae VF39SM and the role of the sensor kinase ChvG in their regulation. J Bacteriol 2010, 192:975-983.

47. Dylan T, Helinski DR, Ditta GS: Hypoosmotic adaptation in Rhizobium meliloti requires $\beta$-(1区2)-glucan. J Bacteriol 1990, 172:1400-1408.

48. Miller-Williams M, Loewen PC, Oresnik IJ: Isolation of salt-sensitive mutants of Sinorhizobium meliloti strain Rm1021. Microbiology 2006, 152:2049-2059.

49. Patankar AV, González JE: An orphan LuxR homolog of Sinorhizobium meliloti affects stress adaptation and competition for nodulation. Appl Environ Microbiol 2009, 75:946-955.

50. Domínguez-Ferreras A, Soto MJ, Pérez-Arnedo R, Olivares J, Sanjuán J: Importance of trehalose biosynthesis for Sinorhizobium meliloti osmotolerance and nodulation of alfalfa roots. J Bacteriol 2009, 191:7490-7499.

51. Domínguez-Ferreras A, Muňoz S, Olivares J, Soto MJ, Sanjuán J: Role of potassium uptake systems in Sinorhizobium meliloti osmoadaptation and symbiotic performance. J Bacteriol 2009, 191:2133-2143.

52. Bélanger $L$, Dimmick KA, Fleming JS, Charles TC: Null mutations in Sinorhizobium meliloti exoS and chvl demonstrate the importance of this two-component regulatory system for symbiosis. Mol Microbiol 2009, 74:1223-1237.

53. Wang C, Kemp J, Da Fonseca IO, Equi RC, Sheng X, Charles TC, Sobral BWS: Sinorhizobium meliloti 1021 loss-of-function deletion mutation in chvl and its phenotypic characteristics. Mol Plant Microbe Interact 2010, 23:153-160.

54. Becker A, Rüberg S, Küster H, Roxlau AA, Keller M, Ivashina T, Cheng HP, Walker GC, Pühler A: The 32-kilobase exp gene cluster of Rhizobium meliloti directing the biosynthesis of galactoglucan: genetic organization and properties of the encoded gene products. J Bacteriol 1997 179:1375-1384.

55. Bahlawane C, Mclntosh M, Krol E, Becker A: Sinorhizobium meliloti regulator MucR couples exopolysaccharide synthesis and motility. $\mathrm{Mol}$ Plant Microbe Interact 2008, 21:1498-1509.

56. Hoang HH, Gurich N, González JE: Regulation of motility by the ExpR/Sin quorum-sensing system in Sinorhizobium meliloti.. J Bacteriol 2008, 190:861-871.

57. Mclntosh M, Krol E, Becker A: Competitive and cooperative effects in quorum-sensing-regulated galactoglucan biosynthesis in Sinorhizobium meliloti. J Bacteriol 2008, 190:5308-5317

58. Ingram-Smith $\mathrm{C}$, Miller $\mathrm{KJ}$ : Effects of ionic and osmotic strength on the glucosyltransferase of Rhizobium meliloti responsible for cyclic $\beta-(1,2)$ glucan biosynthesis. App/ Environ Microbiol 1998, 64:1290-1297.

59. Griffitts JS, Carlyon RE, Erickson JH, Moulton JL, Barnett MJ, Toman CJ, Long SR: A Sinorhizobium meliloti osmosensory two-component system required for cyclic glucan export and symbiosis. Mol Microbiol 2008, 69:479-490.

60. Hynes MF, McGregor NF: Two plasmids other than the nodulation plasmid are necessary for formation of nitrogen-fixing nodules by Rhizobium leguminosarum. Mol Microbiol 1990, 4:567-574.

61. Garcia-de los Santos A, Brom S: Characterization of two plasmid-borne Ips $\beta$ loci of Rhizobium etli required for lipopolysaccharide synthesis and for optimal interaction with plants. Mol Plant Microbe Interact 1997, 10:891-902.

62. Janczarek M, Skorupska A: Regulation of $p s s A$ and $p s s B$ gene expression in Rhizobium leguminosarum bv. trifolii in response to environmental factors. Antonie Van Leeuwenhoek 2004, 85:217-227. 
63. Stanley NR, Lazazzera BA: Environmental signals and regulatory pathways that influence biofilm formation. Mol Microbiol 2004, 52:917-924.

64. Karatan E, Watnick P: Signals, regulatory networks, and materials that build and break bacterial biofilms. Microbiol Mol Biol Rev 2009, 73:310-347.

65. Jackson DW, Simecka JW, Romeo T: Catabolite repression of Escherichia coli biofilm formation. J Bacteriol 2002, 184:3406-3410.

66. Vincent JM: A manual for the Practical Study of Root Nodule Bacteria. International Biological Program handbook no 15 Blackwell Scientific Publications, Ltd, Oxford, UK: 1970.

67. Sambrook J, Fitsch EF, Maniatis T: Molecular Cloning. A Laboratory Manual Cold Spring Harbor, Cold Spring Harbor Press; 1989.

68. Brown CM, Dilworth MJ: Ammonia assimilation by Rhizobium cultures and bacteroids. J Gen Microbiol 1975, 86:39-48.

69. Janczarek M, Urbanik-Sypniewska T, Skorupska A: Effect of authentic flavonoids and the exudates of clover roots on growth rate and inducing ability of nod genes of Rhizobium leguminosarum bv. trifolii. Microbiol Res 1997, 152:93-98

70. Kucharczyk K, Laskowska L, Taylor A: Response of Escherichia coli cell membranes to induction of lambda cl857 prophage by heat shock. Mol Microbiol 1991, 5:2935-2945.

71. Becker A, Küster H, Niehaus K, Pühler A: Extension of the Rhizobium meliloti succinoglycan biosynthesis gene cluster: identification of the exs $A$ gene encoding an $A B C$ transporter protein, and the exs $B$ gene which probably codes for a regulator of succinoglycan biosynthesis. $\mathrm{Mol}$ Gen Genet 1995, 249:487-497.

72. Kannenberg EL, Carlson RW: Lipid A and O-chain modifications cause Rhizobium lipopolysaccharides to become hydrophobic during bacteroid development. Mol Microbiol 2001, 39:379-391.

73. Lesse AJ, Campagnari AA, Bittner WE, Apicella MA: Increased resolution of lipopolysaccharides and lipooligosaccharides utilizing tricine-sodium dodecyl sulfate-polyacrylamide gel electrophoresis. J Immunol Methods 1990, 126:109-117.

74. Vanderlinde EM, Harrison JJ, Muszyński A, Carlson RW, Turner RJ, Yost CK: Identification of a novel $A B C$ transporter required for desiccation tolerance, and biofilm formation in Rhizobium leguminosarum bv. viciae 3841. FEMS Microbiol Ecol 2010, 71:327-340.

75. Leuko S, Legat A, Fendrihan S, Stan-Lotter H: Evaluation of the LIVE/DEAD BacLight kit for detection of extremophilic archea and visualization of microorganisms in environmental hypersaline samples. App/ Environ Microbiol 2004, 70:6884-6886.

76. Beyenal H, Lewandowski Z: Quantifying biofilm structure: facts and fiction. Biofouling 2004, 20:1-23.

77. Ploux L, Beckendorff S, Nardin M, Neunlist S: Quantitative and morphological analysis of biofilm formation on self-assembled monolayers. Colloids and Surfaces B 2007, 57:174-181.

78. Fujishige NA, Kapadia NN, Hirsch AM: A feeling for the micro-organism: structure on a small scale. Biofilms on plant roots. Bot J Linn Soc 2006, 150:79-88.

79. Simon R, Priefer U, Pühler A: A broad host range mobilization system for in vivo genetic engineering: transposon mutagenesis in gram-negative bacteria. Bio/Technology 1983, 1:784-791.

80. Katzen F, Becker A, lelmini MV, Oddo CG, lelpi L: New mobilizable vectors suitable for gene replacement in gram-negative bacteria and their use in mapping of the $3^{\prime}$ end of the Xanthomonas campestris pv. campestris gum operon. Appl Environ Microbiol 1999, 65:278-282.

81. Kovach ME, Elzer PH, Hill DS, Robertson GT, Farris MA, Roop RM, Peterson KM: Four new derivatives of the broad-host-range cloning vector pBBR1MCS, carrying different antibiotic-resistance cassettes. Gene $1995,166: 175-176$

doi:10.1186/1471-2180-10-284

Cite this article as: Janczarek et al:: Rhizobium leguminosarum bv. trifolii $\operatorname{ros} R$ is required for interaction with clover, biofilm formation and adaptation to the environment. BMC Microbiology 2010 10:284.

\section{Submit your next manuscript to BioMed Central and take full advantage of:}

- Convenient online submission

- Thorough peer review

- No space constraints or color figure charges

- Immediate publication on acceptance

- Inclusion in PubMed, CAS, Scopus and Google Scholar

- Research which is freely available for redistribution

Submit your manuscript at www.biomedcentral.com/submit 